\title{
Is Labor Supply Important for Business Cycles?*
}

\author{
Per Krusell $^{\dagger} \quad$ Toshihiko Mukoyama $^{\ddagger} \quad$ Richard Rogerson ${ }^{\S} \quad$ Ayşegül Şahin $₫$
}

December 2011

\begin{abstract}
We build a general equilibrium model that features uninsurable idiosyncratic shocks, search frictions and an operative labor supply choice along the extensive margin. The model is calibrated to match the average levels of gross flows across the three labor market states: employment, unemployment, and non-participation. We use it to study the implications of two kinds of aggregate shocks for the cyclical behavior of labor market aggregates and flows: shocks to search frictions (the rates of job finding and job loss) and shocks to the return on the market activity (any factors affecting aggregate productivity). We find that both kinds of shocks are needed to explain the labor market data, and that an active labor supply channel is key. A model with friction shocks only, calibrated to match unemployment fluctuations, accounts for only a small fraction of employment fluctuations and has counterfactual cyclical predictions for participation.

Keywords: Labor Supply, Labor Market Frictions, Business Cycles

JEL Classifications: E24, J22, J64
\end{abstract}

${ }^{*}$ We thank Marcelo Veracierto and seminar participants as well as conference participants at the Asian Meeting of the Econometric Society (2011), Chicago Fed, HEC Montreal, Hitotsubashi Macro Econometrics Conference, National University of Singapore, Search and Matching Network Conference (2011), NBER Summer Institute (2011), NBER Conference on Macroeconomics Across Time and Space (2011), SED (2011), Oslo University, Norges Bank, European University Institute, Bank of Korea, St. Louis Fed, San Francisco Fed, NBER Economic Fluctuations and Growth Meeting (2011), and University of Pennsylvania for useful comments. We thank Joe Song for excellent research assistance. Krusell thanks the NSF for financial support, Mukoyama thanks the Bankard Fund for Political Economy for financial support, and Rogerson thanks the NSF and the Korean Science Foundation (WCU-R33-10005) for financial support. The views expressed in this article are those of the authors and do not necessarily reflect those of the Federal Reserve Bank of New York or the Federal Reserve System. Corresponding author: Richard Rogerson. Address for correspondence: Woodrow Wilson School, Princeton University, Princeton, NJ 08544. Phone: 609-258-4839 Fax: 609-258-5349. Email: rdr@princeton.edu.

${ }^{\dagger}$ IIES, CAERP, CEPR, and NBER

${ }^{\ddagger}$ University of Virginia and CIREQ

${ }^{\S}$ Princeton University, NBER and AEI

`Federal Reserve Bank of New York 


\section{Introduction}

The idea that labor supply plays a key role in business cycle fluctuations has been controversial ever since it was put forth by Lucas and Rapping (1969). One recurring challenge - the explicit consideration of unemployment - was recently revived by Hall (2008) in the context of modern unemployment theory. He argues that although aggregate models with indivisible labor (e.g., Hansen (1985)) can generate large fluctuations in employment via labor supply responses, they are inconsistent with the US evidence that roughly $80 \%$ of business cycle fluctuations in employment show up as offsetting changes in unemployment rather than changes in participation. Hall (2009) consequently proposes a model of the macroeconomy in which the labor supply margin for employment is not operative by assumption: participation is exogenously fixed and employment is completely determined by search frictions (job-finding and job-loss rates).

In this paper we critically examine the view that empirical evidence on unemployment and participation implies a minimal role for labor supply in the determination of employment. We develop a macroeconomic model with a detailed description of the labor market, along with descriptions of individuals' saving and working opportunities that are in line with applied work in consumption and labor studies. We demand of this model to match the main labormarket facts - the gross flows of workers across the three labor market states (employment, unemployment, and non-participation)—on average over time.

In order to generate aggregate volatility, we then subject this economy to two types of aggregate shocks: shocks to search frictions (the rates of job finding and job loss) and shocks to the return on the market activity (any factors affecting aggregate productivity). Our central findings are threefold: (i) this model provides an excellent account of the business cycle fluctuations in employment, unemployment and participation, as well as in labor market 
flows; (ii) a model with only shocks to frictions cannot account for the labor market data; and (iii) the fluctuations in employment are chiefly a result of an operative labor supply.

One broad conclusion of our paper, thus, is that it is important to explicitly model participation in order to understand the underlying forces that shape labor market fluctuations. Beyond the specific findings that we offer, several other arguments suggest that the participation decision ought to be taken seriously. First, even if participation did not change at all over the business cycle, it is surely important to understand why. The gross flows are large: many individuals move between participation and non-participation each month, suggesting that this is surely an operative margin for many individuals. Additionally, there are many examples in the data of large responses in participation over time at the aggregate level. ${ }^{1}$ Second, as we detail later in the paper, the relative constancy of the aggregate participation rate hides the fact there are large changes in the flows between participation and non-participation over the business cycle that turn out to mostly offset each other. Third, although participation fluctuates relatively little in the US, this is much less true for some other OECD economies. ${ }^{2}$ Similarly, the importance of participation fluctuations varies across demographic groups within the US. To us, these three reasons suggest that it is more reasonable to consider participation as endogenous, and responsive to economic incentives, rather than to treat it is exogenously fixed.

There is widespread agreement that a good theory of labor market fluctuations should have solid microfoundations. Following more than forty years of applied research on labor market dynamics, we believe that the appropriate microfoundations in this context should include a theory of gross worker flows among the three labor market states of employment,

\footnotetext{
${ }^{1}$ An obvious example is the large secular increase in female participation rates. Other examples include large declines in participation rates for low-skilled males and for older males (the latter occuring prior to 1995).

${ }^{2}$ See, for example, Rogerson and Shimer (2010).
} 
unemployment and non-participation. A key building block of our model of gross flows is a theory of individual labor supply in the presence of idiosyncratic shocks, trading frictions and incomplete markets in which preferences embody empirically reasonable income and substitution effects. Each of these features plays an important role. Idiosyncratic shocks are essential in accounting for the empirical features of the gross flows data. Trading frictions allow us to distinguish between the unemployed and the nonparticipants. Incomplete markets rule out trade in employment lotteries and insurance against idiosyncratic shocks, thereby forcing individuals to self insure by accumulating assets. While this sort of market incompleteness has been found to not matter much for some business cycle properties, it is evident from Galí et al. (2011) that this feature is important for the cyclical properties of participation. Many models of unemployment assume linear utility, and hence rule out income effects. It is well known in the applied business cycle literature that income effects, which are needed for understanding saving as well as insurance, play an important quantitative role.

The calibration of the basic parameters of our model - preferences, technology, and frictions - so as to be consistent with the average behavior of the US economy follows standard practice in the modern business cycle literature. The calibration of our aggregate shocks is designed to "give the model a chance", as in Kydland and Prescott (1982): the shocks to the return to market activity and to search frictions are set to generate realistic movements in a subset of the labor market aggregates. This calibration results in shocks that are in line with existing literatures. We then examine the economy's behavior for all of the macroeconomic variables, including all labor market flows.

Our results imply that Hall's reasoning is misleading. That is, even if the fluctuations in search frictions in our model are assumed large enough so as to account for observed fluctuations in unemployment, labor supply responses significantly dampen their effect on 
employment. When it is hard to find a job, those workers with a job stay on longer. Thus, aggregate employment does not fall much at all, participation becomes countercyclical, and the cyclical fluctuations in participation become large - three features that all are at odds with the data. The key message is that the presence of an empirically plausible labor supply response along the extensive margin-plausible in that it can account for average flowshas important implications for evaluating theories in which labor supply is not necessarily assigned a large role. Put somewhat differently, exogenously shutting down the participation margin hides the fact that such a model contains quantitatively important forces with counterfactual predictions.

Our finding that a specification with shocks to both the return to market activity and jobfinding and job-loss rates gives a very reasonable account for all of the cyclical labor market facts, i.e., for stocks as well as flows, is non-trivial and quite surprising. When we decompose the resulting fluctuations into the contribution attributed to each shock we find that the dominant source of employment fluctuations is the shock to the return to overall market activity, whereas the dominant source of unemployment fluctuations is the shock to the job offer arrival rate. Shocks to the job-loss rate play only a minor role overall. Moreover, shocks to the job-finding rate account for much of the fluctuations in measured transition rates from employment to unemployment. In short, the relative constancy of the participation rate over the business cycle is not evidence against the importance of labor supply as a driving force behind aggregate fluctuations.

Given its focus on business cycle fluctuations in an aggregate three state model of the labor market, our analysis is closely related to recent similar analyses by Tripier (2004), Veracierto (2008), Galí et al. (2011), Christiano et al. (2010), Shimer (2011) and Haefke and 
Reiter (2011). ${ }^{3}$ Relative to these authors, one key distinction of our analysis is its focus on gross flows. Each of these papers focuses exclusively on the fluctuations in the levels of $E$, $U$ and $N$ and pays no attention to the properties of the underlying flows, either in steady state or over the cycle. Our setting also places stronger emphasis on individual heterogeneity and the uninsurability of idiosyncratic shocks. Relative to Tripier and Veracierto, we allow for shocks to labor market frictions. Relative to Shimer (2011), the job-finding frictions are assumed exogenous here; thus, we focus on the economy's response to cyclical variations in job-finding and job-loss rates as opposed to on their origins.

An outline of the paper follows. In the next section we document the key business cycle facts for gross worker flows among the three labor market states for the US over the period 1968-2009. Section 3 describes our theoretical framework. Section 4 presents our quantitative results on the effects of different aggregate shocks on gross worker flows and Section 5 concludes.

\section{Business Cycle Fluctuations in the Labor Market}

The early real business cycle literature focused on a small set of second moments that were thought to represent first order properties of business cycle fluctuations, including the relative volatility and comovement between aggregate series such as output $(Y)$, consumption, investment, and employment. While this has been useful for focusing and organizing quantitative research on business cycles, we expand the set of labor market statistics considered along two dimensions in order to better understand and distinguish between the forces that shape labor market fluctuations. First, as in recent work noted in the introduction, we include information on how non-employed workers are categorized between the states of unemployment and

\footnotetext{
${ }^{3}$ Alternatively, our model can be viewed as adding search frictions to the model of Chang and Kim (2006), that features idiosyncratic shocks, indivisible labor and incomplete markets.
} 
out of the labor force. Second, and differently than the studies just mentioned, we explicitly consider the gross flows of workers between states. ${ }^{4}$ These flows have long been recognized as important; see, e.g., Blanchard and Diamond (1990). From the perspective of connecting an aggregate model of the labor market to micro data, we believe the behavior of individual labor market flows is of first order importance.

Table 1 presents data for average monthly transition rates among the three labor market states: employment $(E)$, unemployment $(U)$, and not in the labor force $(N)$. Details regarding data sources and construction are provided in Appendix A.1.

Table 1

\begin{tabular}{|c|c|c|c|}
\hline \multicolumn{4}{|c|}{ US Transition Rates 1968-2009 } \\
\hline FROM & & TO & \\
\hline & $E$ & $U$ & $N$ \\
\hline$E$ & 0.954 & 0.016 & 0.030 \\
\hline$U$ & 0.270 & 0.508 & 0.222 \\
\hline$N$ & 0.048 & 0.027 & 0.925 \\
\hline
\end{tabular}

The transition rates among all three states are very large. While a large literature has previously emphasized the high transition rates between $E$ and $U$, we want to highlight the large transition rates into and out of the labor force. Each month, more than $7 \%$ of the workers who are out of the labor force will enter the labor force in the subsequent month. We detail later in the paper that part of the measured transition rates between $N$ and $U$ may be the result of classification error, but even if we focus only on the flow of workers from $N$ to $E$, the rate is still almost five percent per month. The key point is that the decision to move between participation and non-participation seems an operative margin for a large number of individuals.

Table 2 presents the richer set of labor market business cycle statistics that we study. Note

\footnotetext{
${ }^{4}$ Garibaldi and Wasmer (2005) is a recent paper that studies gross flows in a three state model. Differently from us, they assume linear utility and do not consider business cycle fluctuations.
} 
that $u$ denotes the unemployment rate, $U /(E+U)$, and $l f p r$ is the labor force participation rate, $(E+U) /(E+U+N)$.

Table 2

\begin{tabular}{cccccccccc}
\hline \hline \multicolumn{10}{c}{ Cyclical Properties of US Labor Market Statistics } \\
\hline & $E$ & $u$ & lfpr & $f_{E U}$ & $f_{E N}$ & $f_{U E}$ & $f_{U N}$ & $f_{N E}$ & $f_{N U}$ \\
$\operatorname{std}(x) / \operatorname{std}(Y)$ & .68 & 7.6 & .21 & 5.4 & 2.0 & 4.9 & 3.8 & 2.7 & 4.0 \\
$\operatorname{corrcoef}(x, Y)$ & .84 & -.87 & .46 & -.82 & .33 & .78 & .78 & .64 & -.70 \\
$\operatorname{corrcoef}\left(x, x_{-1}\right)$ & .95 & .92 & .72 & .73 & .20 & .84 & .73 & .41 & .75 \\
\hline \hline
\end{tabular}

Our notational convention is that $f_{i j}$ denotes the fraction of workers that moved from state $i$ in the previous period to state $j$ in the current period. Note that although labor market data are available at monthly frequency, NIPA data is available only at quarterly frequency. In order to evaluate the correlation of labor market flows with output we have generated labor market transition rates at quarterly frequency by setting the quarterly value equal to the average of the three monthly values within the quarter. To produce business cycle statistics we then log and HP filter the data.

Several features are worth noting. First, the transition rates between $E$ and $U$ exhibit roughly equal volatility, are very persistent and are strongly correlated with the cycle, with $f_{E U}$ being strongly countercyclical and $f_{U E}$ being strongly procyclical. Second, fluctuations in the unemployment rate are more than an order of magnitude larger than fluctuations in the participation rate. The former is strongly countercyclical whereas the latter is weakly procyclical. It follows that most of the cyclical fluctuations in employment show up as offsetting changes in unemployment as opposed to changes in participation.

We next turn to some patterns that are less well known. ${ }^{5}$ Although the stock of nonparticipants does not vary that much over the business cycle, the flows between non-participation

\footnotetext{
${ }^{5}$ Note that there are some differences between the statistics that we report here and those that are used in several studies. For example, Shimer (2005) focuses on the flows into and out of unemployment without distinguishing whether the workers that enter unemployment come from employment or out of the labor force, or whether the workers that leave unemployment leave to employment or out of the labor force.
} 
and the other states exhibit pronounced movements at business cycle frequencies. For example, whereas the fluctuations in the participation rate are an order of magnitude smaller than the fluctuations in the unemployment rate, the fluctuations in the transition rates into and out of non-participation are of roughly the same order of magnitude as the those in the much-studied flows between $E$ and $U$. The cyclicality of the flows between $U$ and $N$ also exhibits an interesting pattern. Specifically, the transition rate from $U$ to $N$ has the same cyclical correlation as the transition rate from $U$ into $E$, and the transition rate from $N$ into $U$ has the same cyclical pattern as the transition rate from $E$ into $U$. That is, both flows into $U$ have the same cyclical properties, as do both flows out of $U$.

The transition rate from $N$ into $E$ is strongly procyclical, just as is the transition rate from $U$ into $E$, though it is somewhat less volatile. Looking only at these two flows, one would not be led to infer that the participation rate plays only a minor role in accounting for employment fluctuations. The reason that the stock of participation does not move more over the cycle is because of the offsetting effect of an increased $U$ to $N$ transition rate during good times.

\section{Theory}

As is standard in the business cycle literature, we consider business cycles as resulting from aggregate shocks that cause the economy to fluctuate around the steady state equilibrium that would result in the absence of aggregate shocks. We first describe our model.

\subsection{Economy}

In addition to developing a framework appropriate for the issue at hand, our broader aim is to provide a realistic description of the main economic events for a household as it goes through time. We thus formulate a model that arguably captures the key income-relevant 
events for a household and its main vehicles for dealing with these events: it can hold an asset, although restrictedly, thus being able to insure itself but only to some extent. Importantly, our specification of preferences allows for empirically reasonable income and substitution effects. One advantage of this approach is that it allows us to build a solid connection with micro data and the rich set of studies on individuals; we will use this in the calibration of our model. We believe that our model is the first macroeconomic model with these features. While the model is somewhat minimalist, our earlier work Krusell et al. (2011) shows that it is capable of accounting for the average behavior of labor market flows, therefore making it a natural benchmark for an initial quantitative assessment of how frictions interact with labor supply in the business cycle context.

The economy is populated by a continuum of workers with total mass equal to one. All workers have identical preferences over streams of consumption and time devoted to work given by:

$$
E_{t} \sum_{t=0}^{\infty} \beta^{t}\left[\log \left(c_{t}\right)-\alpha e_{t}\right]
$$

where $c_{t} \geq 0$ is consumption in period $t, e_{t} \in\{0,1\}$ is time devoted to work in period $t$, $0<\beta<1$ is the discount factor and $\alpha>0$ is the disutility of work. Individuals are subject to idiosyncratic shocks that affect the static payoffs of working in the market relative to not working. While many distinct shocks may have this feature, including, for example, shocks to market opportunities, shocks to home production opportunities, health shocks, family shocks, preference shocks, etc..., we represent the net effect of all of these shocks as a single shock, and model it as a shock to the return to market work. ${ }^{6}$ In particular, letting $z_{t}$ denote the quantity of labor services that an individual contributes if working, we assume an $A R(1)$

\footnotetext{
${ }^{6}$ Alternatively, we could assume that the only shock is to the disutility of working. Either way, the key economic mechanism is that the shock serves to change the relative return to working versus not working. In fact, Garibaldi and Wasmer (2005) model home productivity shocks as the driving force.
} 
stochastic process in logs:

$$
\log z_{t+1}=\rho_{z} \log z_{t}+\varepsilon_{t+1}
$$

where the innovation $\varepsilon_{t}$ is a mean zero normally distributed random variable with standard deviation $\sigma_{\varepsilon}$. This process is the same for all workers, but realizations are $i i d$ across them.

Frictions in the labor market are captured by two exogenous variables: $\lambda_{t}$ and $\sigma_{t}$, where $\lambda$ is the employment opportunity arrival rate and $\sigma$ is the employment separation rate. These values are common to all individuals but may fluctuate randomly over time. To understand how the frictions impact the economy it is useful to think that the economy consists of two islands: a production island and a non-production island. An individual begins period $t$ on the production island if $e_{t-1}=1$, and otherwise begins on the non-production island. Each individual on the production island observes the realization of an iid separation shock: with probability $\sigma$ the individual is relocated to the non-production island. And each individual who is now on the non-production island, either because they started the period there or were relocated there by the separation shock, observes the realization of an iid employment opportunity shock that with probability $\lambda$ relocates them to the production island. Given our timing assumption, an individual who suffers the $\sigma$ shock will not necessarily spend a period in nonemployment but can be reemployed "instantaneously".

Once these and the other shocks have been realized, individuals make their labor supply and consumption decisions, though only individuals on the production island can choose $e$ equal to 1. An individual on the production island who chooses not to work will then be relocated to the leisure island at the end of period $t$ and will therefore not have the opportunity to return to the production island until receiving a favorable employment opportunity shock. 
The production technology is described by a Cobb-Douglas aggregate production function:

$$
Y_{t}=Z_{t} K_{t}^{\theta} L_{t}^{1-\theta}
$$

where $K_{t}=\int k_{i t} d i$ is aggregate input of capital services and $L_{t}=\int e_{i t} z_{i t} d i$ is aggregate input of labor services. $Z_{t}$ is a standard technology shock. Output can be used either as consumption or investment, and capital depreciates at rate $\delta$.

Our setting thus leaves open what underlying factors cause the frictions in job finding and job loss, as well as what the underlying sources of productivity fluctuations may be - and whether there is a connection between these. One way to view our approach is that while we recognize the difficulty for workers of finding and retaining jobs, and hence accept the notion of involuntary unemployment, we are for the present purpose - i.e., the evaluation of the role of labor supply over the cycle - agnostic as to the exact model generating these frictions.

\subsection{Equilibrium}

We formulate equilibrium recursively. An individual's state consists of his or her location at the time that the labor supply decision needs to be made, the level of asset holdings, and productivity. The aggregate state will include any information that individuals have and is useful in forecasting prices. We denote this information by $\Omega$. In this model, $\Omega$ includes both exogenous aggregate shocks $(Z, \lambda$, and $\sigma)$ and the distribution of wealth and labor-market status across all individuals. Since the notion of recursive competitive equilibrium that we employ is standard we do not include a formal definition of the consistency conditions, in particular for how $\Omega$ evolves over time. ${ }^{7}$ We use the notation $\Omega^{\prime}(\Omega)$ to denote this evolu-

\footnotetext{
${ }^{7}$ In all essential respects we follow Krusell and Smith (1998). Note that because firms make zero profits here, one does not need to consider firm equity, as in Krusell, Mukoyama, and Şahin (2010), where consumers consequently have a more demanding portfolio problem.
} 
tion. We do, however, present detailed information on the Bellman equations for individual workers.

Let $W(k, z, \Omega)$ and $N(k, z, \Omega)$ be the maximum values for an individual who works and does not work, respectively, given that he or she has individual values of $(z, k)$ and the aggregate state is $\Omega$. Define $V(k, z, \Omega)$ by:

$$
V(k, z, \Omega)=\max \{W(k, z, \Omega), N(k, z, \Omega)\}
$$

The Bellman equations for $W$ and $N$ are given by:

$$
\begin{gathered}
W(k, z, \Omega)=\max _{c, k^{\prime}}\left\{\log (c)-\alpha+\beta E_{z^{\prime}, \Omega^{\prime}}\left[(1-\sigma(1-\lambda)) V\left(k^{\prime}, z^{\prime}, \Omega^{\prime}(\Omega)\right)+\sigma(1-\lambda) N\left(k^{\prime}, z^{\prime}, \Omega^{\prime}(\Omega)\right)\right]\right\} \\
\text { s.t. } c+k^{\prime}=r(\Omega) k+(1-\tau) w(\Omega) z+(1-\delta) k+T(\Omega), c \geq 0, k^{\prime} \geq 0
\end{gathered}
$$

and

$$
\begin{gathered}
N(k, z, \Omega)=\max _{c, k^{\prime}}\left\{\log (c)+\beta E_{z^{\prime}, \Omega^{\prime}}\left[\lambda V\left(k^{\prime}, z^{\prime}, \Omega^{\prime}(\Omega)\right)+(1-\lambda) N\left(k^{\prime}, z^{\prime}, \Omega^{\prime}(\Omega)\right)\right]\right\} \\
\text { s.t. } c+k^{\prime}=r(\Omega) k+(1-\delta) k+T(\Omega), c \geq 0, k^{\prime} \geq 0 .
\end{gathered}
$$

In these expressions, the expectation with respect to $\Omega^{\prime}$ refers to the stochastic aggregate components in $\Omega$ next period: next period's values for $Z, \lambda$, and $\sigma$. Note that the constraint $k^{\prime} \geq 0$ reflects that there is no borrowing.

\section{Quantitative Analysis}

We now begin the quantitative analysis of our model economy, starting with the calibration. The calibration is of two sorts: we need to select the driving processes for our main business cycle shocks, $Z, \lambda$, and $\sigma$, and we need to select the rest of the model parameters. We begin 
with the latter part, which is accomplished by looking at the model's steady state. Thus, the basic parameters here are selected to match long run aggregate facts and average labor market facts: stocks and flows across the three states.

\subsection{Steady State Calibration}

A key aspect of the steady state calibration procedure is to choose parameters so that the distribution of workers across the three labor market states and the flows of workers between states in the steady state equilibrium are similar to their average values over time in the US economy, that is, to ensure that the calibrated model has the requisite microfoundations. Official statistics divide non-employed workers into the two categories of unemployed and out of the labor force based primarily on how they answer a question regarding active search in the previous four weeks. Although our model does not feature a search decision, it can be mapped into this definition. Specifically, if active search is a discrete decision and the cost of search is very small, the decision to search amounts to asking an individual if he or she would prefer working to not working. ${ }^{8}$ Among those individuals in our model who are not employed in period $t$, we will label anyone who would prefer to be employed "unemployed" and anyone who would prefer to not work "out of the labor force". 9

Because the calibration is effectively identical to that in Krusell et al. (2010, 2011), details are provided in Appendix A.2. Table 3 summarizes the calibrated values and the

\footnotetext{
${ }^{8}$ Given evidence from time use data on the amount of time devoted to search, we think it is reasonable to assume that the cost of active search is very small. An extension of this model to incorporate search costs is feasible, though it would require significantly more computer time. As discussed later in the paper, we conjecture that if search costs of the size estimated in the literature are allowed, the model would deliver very similar results to those obtained here.

${ }^{9}$ In our earlier work we argued that a more natural way to connect the model to the data was to adopt a more inclusive definition of unemployment in the data, based on the desire to work rather than active search. Nonetheless, we found that the broader definition was not substantively important either in terms of the features in the data or the ability of the model to account for the data. We revert to the standard definition of unemployment in this paper because of the difficulty in getting a longer time series for flows between the states with the broader measure.
} 
various targets used in the calibration.

Table 3

\begin{tabular}{ccccccccc}
\hline \hline \multicolumn{8}{c}{ Benchmark Calibration } \\
\hline \multicolumn{10}{c}{ Targets } \\
\hline \multicolumn{10}{l}{$\frac{U}{Y}=.20, \frac{r K}{Y}=.3, \frac{E}{P}=.610, \frac{U}{E+U}=.061,1+r-\delta=1.04^{1 / 12}, E \rightarrow E=.954$} \\
\hline \hline & $\delta$ & $\beta$ & $\alpha$ & $\rho_{z}$ & $\sigma_{\varepsilon}$ & $\lambda$ & $\sigma$ & $\tau$ \\
\hline 30 & .0067 & .9967 & .61 & .9931 & .1017 & .44 & .013 & .30 \\
\hline \hline
\end{tabular}

One issue that was not explicitly considered in our earlier work that we want to discuss here concerns classification error. There is strong evidence in the literature (see, e.g., Poterba and Summers (1986)) that classification errors lead to spurious flows, especially between unemployment and not in the labor force. One strategy for addressing this would be to try to purge the official data of measurement error. Unfortunately, this is not feasible. The survey that Poterba and Summers used to estimate the extent of classification error on transition rates was discontinued shortly thereafter. Instead, we deal with this issue by adding some measurement error to the data generated by our model. We provide details on this procedure in Appendix A.3 and show that with an empirically plausible amount of measurement error the model does a much better job of matching the flows between $U$ and $N$. While classification error is important in matching the average behavior of flows in the data, we show in Appendix A.3 that it is not important for our key findings about business cycle fluctuations.

While our calibrated model is able to reproduce the key features of both aggregate facts and labor market flows in the US economy, we think it is also relevant to note the minimalist nature of the model. At the aggregate level, the basic structure is that of the standard one-sector neoclassical growth model. We have not included features such as adjustment costs that are common in current medium scale DSGE models. At the micro level we have abstracted from empirically reasonable features such as an interaction between individual 
market productivity and employment status, or interaction between individual productivity and the two frictional parameters. We have also abstracted from the choice of search intensity. Note also that we only model frictions as they explicitly influence movements between nonemployment and employment. That is, we do not explicitly model the process of job-to-job transitions. To the extent that these occur, they are subsumed into the evolution of the idiosyncratic shocks to $z$.

While all of these features could be added to the framework, we have instead opted for parsimony. Our simple model is able to capture the key features of the average flow data, and therefore seems a natural starting point for the analysis of aggregate fluctuations in a model that explicitly models the flows. Incorporating the additional features mentioned above is something that we leave for future work.

\subsection{Business Cycle Analysis}

In this section we subject the calibrated steady state model of the previous section to aggregate shocks. While we could subject the model to various sorts of aggregate shocks we will limit our attention to two types of aggregate shocks. In our steady state model we found that idiosyncratic shocks to employment opportunities and the benefit of working relative to not working were sufficient to capture average movements of workers across the three labor market states. Here we will focus on aggregate shocks to these same two factors. We capture aggregate shocks to the relative value of working versus not working by our TFP shock $Z_{t}$. This is obviously a simple way to generate a common increase in the benefit of working relative to not working. However, to the extent that there are other mechanisms for achieving this same outcome (e.g., informational shocks coupled with some form of increasing returns to scale) we do not necessarily insist on the interpretation of this driving force as a true technological shock. We capture aggregate shocks to frictions through stochastic movements 
in $\lambda$ and $\sigma$. Note that we take the changes in these frictional parameters to be exogenous. Our goal at this point is to assess the ability of various types of shocks to generate outcomes that match those found in the data, rather than the analysis of how these shocks arise.

We proceed by considering a sequence of different assumptions about the aggregate shocks. We first consider the special case in which labor market frictions are random but aggregate productivity is not. That section makes precise how the labor supply margin plays an important role in this economy and how the equilibrium outcome involves counterfactual behavior for participation. We next shut down the shocks to frictions and instead look at TFP shocks only. Here as well, the model's predictions are far from the data in a number of respects, particularly for both unemployment and worker flows. Finally, we present our "benchmark", which is a model with shocks to both frictions and TFP.

The details of how the aggregate shocks are chosen are presented in each section. Prior to describing our findings, we also briefly summarize how the model is solved. The present model is similar in spirit to that in Krusell and Smith (1998), where there is no participation decision. As a result, here the consumer's problem is considerably more nonlinear, as there are always consumers (i) deeply in the non-participation region, (ii) deeply in the participation region, and (iii) near indifference between participating and not participating in the labor market.

The model is computed using Krusell and Smith's (1998) limited information approachwe restrict $\Omega$ to a few variables that can easily be kept track of, let the consumers make decisions based on this limited information and simple forecasting rules that are based on this information, and check whether their forecast is consistent with what actually happens in the economy that consists of these consumers. We describe the procedure, and document that it works very well, in Appendix A.3. 


\subsubsection{Results 1: The Model With Friction Shocks Only}

In this subsection we argue that use of two-state models that completely abstract from labor supply considerations along the extensive margin can deliver misleading conclusions regarding the kinds of shocks that account for labor market fluctuations. Consider, for example, the simple two-state model that Shimer (2005) used in his analysis. By construction, fluctuations in $E$ and $U$ are mirror images of each other. Since in the data there is relatively little movement in the participation rate, it follows that if one takes the flow rates between $E$ and $U$ as measured in the data and exogenously feeds them into the model, one will approximately reproduce the fluctuations in $E$ and $U$ found in the data. Researchers who view the world through the lens of such a two-state model will conclude that a sufficient condition for understanding the key features of labor market fluctuations is to understand movements in the two flow rates between $E$ and $U$. In this section we examine this conclusion in the context of our three state model and show that it no longer holds.

Calibration of the Shocks To proceed we assume that both $\lambda$ and $\sigma$ follow symmetric two-state Markov processes with persistence parameters $\rho_{\lambda}$ and $\rho_{\sigma}$ respectively. Specifically, if we let $\bar{\lambda}$ and $\bar{\sigma}$ denote the calibrated steady state values of the two frictions, we assume that $\lambda$ takes values in the set $\left\{\lambda_{G}, \lambda_{B}\right\}$ where $\lambda_{G}=\bar{\lambda}+\varepsilon_{\lambda}$ and $\lambda_{B}=\bar{\lambda}-\varepsilon_{\lambda}$, and similarly that $\sigma$ takes values in the set $\left\{\sigma_{G}, \sigma_{B}\right\}$ where $\sigma_{G}=\bar{\sigma}-\varepsilon_{\sigma}$ and $\sigma_{B}=\bar{\sigma}+\varepsilon_{\sigma}$. For simplicity, we assume that the two shocks are perfectly (negatively) correlated, so that the aggregate realizations are either both good or both bad. We therefore assume that $\rho_{\lambda}=\rho_{\sigma}=\rho$, and consistent with much of the real business cycle literature assume that $\rho=.983$. The values of $\varepsilon_{\lambda}$ and $\varepsilon_{\sigma}$ are then set so that in the simulated equilibrium, we match the volatility of $f_{E U}$ and $f_{U E}$ reported in Table 3 . The calibrated values are $\left(\lambda_{G}, \lambda_{B}\right)=(0.51,0.37)$, 
$\left(\sigma_{G}, \sigma_{B}\right)=(0.01254,0.01346)$.

Cyclical Properties of Stocks By construction, the model accounts perfectly for the cyclical movements in the two rates $f_{E U}$ and $f_{U E}$. But how will it perform along other dimensions? As a first step in answering this question Table 4 examines the cyclical properties of the three stocks: $E, U$ and $N$ as well as output.

Table 4

\begin{tabular}{lccc|ccc}
\hline \hline \multicolumn{6}{c}{ Behavior of Stocks with Friction Shocks Only } \\
\hline \multicolumn{4}{c}{ Volatilities: } & std $(x)$ & \multicolumn{3}{c}{ Correlations: corrcoef $(x, Y)$} \\
\hline Data & $u$ & lfpr & $E$ & $u$ & lfpr & $E$ \\
Frictions & .12 & .003 & .011 & -.87 & .46 & .84 \\
\hline \hline
\end{tabular}

Note first that this model accounts for almost all of the fluctuations in unemployment that are found in the data, and that they are strongly negatively correlated with output fluctuations. Based on this, one could conclude that the model with only shocks to frictions does a good job of accounting for unemployment fluctuations. However, Table 4 also reveals that the model accounts for less than $20 \%$ of the movements in employment. The failure to account for employment fluctuations is mirrored in some counterfactual predictions for participation: participation rate fluctuations in the model are more than two times as large as in the data, and are strongly countercyclical instead of mildly procyclical.

The fact that employment fluctuations are not a mirror image of unemployment fluctuations reflects the presence of an operative labor supply margin, i.e., a participation decision, that provides individuals with the opportunity to make choices that partially offset the direct effect of changes in frictions. As a first step in exploring the underlying economic mechanism, consider how the participation region changes as the economy moves from the bad aggregate state to the good aggregate state. Figure 1 illustrates this by plotting the optimal decision rules for the two different realizations of the aggregate friction shocks, evaluated at the mean 
level of the other aggregate states. Specifically, the figure partitions the space of individual state variables into participation and non-participation regions.

Figure 1: Cut-off wealth and productivity levels for the model with frictions shocks only

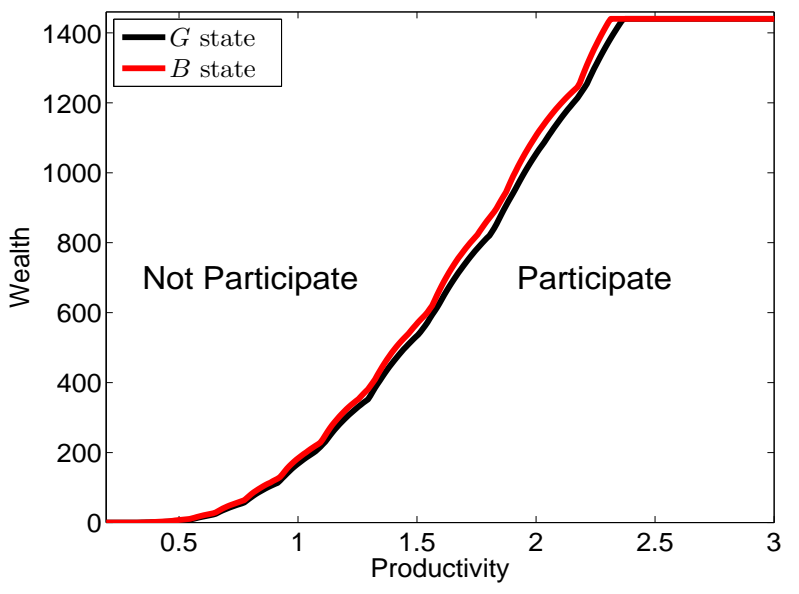

Because the other aggregate state variables (the capital stock and the lagged capital to labor ratio in our solution method) will also change over the cycle, this figure does not capture the changes in decision rules associated with the change in these variables. However, to the extent that the other aggregate state variables are not that volatile and change slowly over time, the figure does capture the relevant first order changes in decision rules over the cycle.

The important message from Figure 1 is that when frictions become more severe, thereby making it more difficult to obtain employment, individuals respond by enlarging the set of individual states in which they will work. ${ }^{10}$ Note that this manifests itself in two ways: individuals who are employed will be less likely to move out of employment in response to idiosyncratic shocks, and some individuals who are not employed will decide to accept employment opportunities under conditions that they previously would not. Also note that both the heterogeneity in wealth and idiosyncratic productivity play active roles: the curve

\footnotetext{
${ }^{10}$ In Krusell et al. (2010) we demonstrated that this effect was quantitatively important in terms of steady state outcomes. Here we see that the effect is quantitatively significant in a business cycle context as well.
} 
describing indifference is neither vertical nor horizontal.

This effect is intuitive. A key desire for individuals in this economy is to arrange the timing of work to coincide with periods of high individual productivity. Frictions interfere with an individual's ability to achieve the desired timing. When frictions become more severe, individuals respond by expanding the set of conditions under which they will work if given the opportunity, i.e., by becoming less choosy. The implication is that participation will be countercyclical. While the magnitude of this effect will depend on the density of individuals around the boundary of the two regions, this figure illustrates the main economic mechanism at work. It is also important to emphasize that the magnitude of this effect depends critically on the size of income and substitution effects in labor supply. In particular, a model with linear utility and hence no income effects will underestimate the desire of individuals to work more in response to changes that lower income.

Transition Dynamics To gain additional insight into the workings of the model it is instructive to examine how the transition rates between the various labor market states respond when the aggregate state changes from the bad state to the good state. Specifically, we simulate the economy for a large number of periods and individuals and pick a specific time interval where the economy moves from a bad state to a good state. ${ }^{11}$ We then calculate the log deviation of individual transition rates. The results are shown in Figure 2.

The patterns found in Figure 2 are all intuitive. We begin with the flows between $E$ and $U$, which are the simplest. To move from $E$ to $U$ across adjacent periods three things must happen: a worker must suffer a separation, not receive a new employment opportunity, and not suffer an idiosyncratic shock that changes their desire to work. The probability of the

\footnotetext{
${ }^{11}$ We simulate the economy for 5,000 periods and discard the initial 1,000 periods. The interval we selected corresponds to a period where the economy moves from a $B$ state in period 20 to a $G$ state that lasts for 200 periods.
} 
Figure 2: Response of flows to a positive shock for the model with frictions shocks only
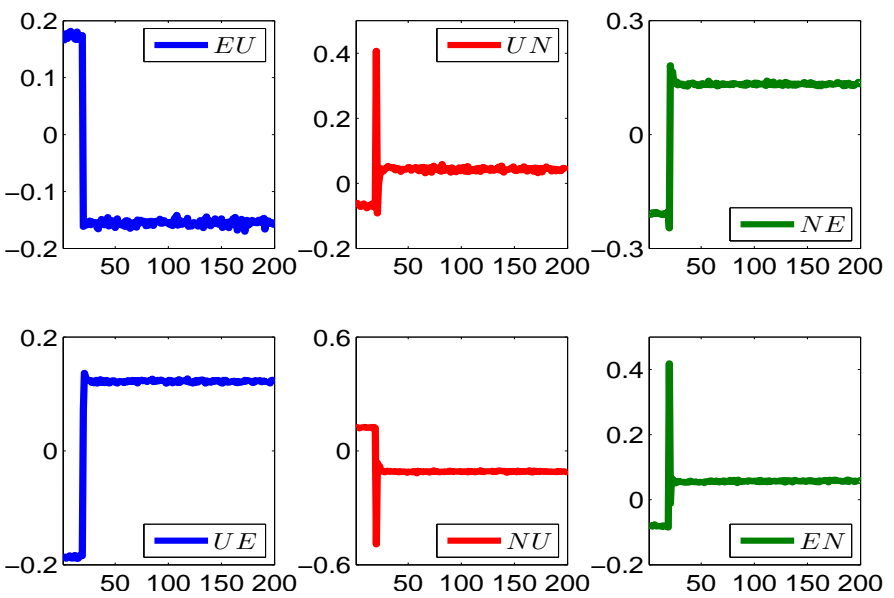

first two events is $\sigma(1-\lambda)$, which is clearly higher in the good state. We discuss the third event in more detail below, and argue that it moves in the opposite direction. However, its effect is second order compared to the change in $\lambda$. Similarly, to move from $U$ to $E$ across adjacent periods requires that two things happen: the individual must receive a work opportunity, and not suffer an idiosyncratic shock that changes their desire to work. Once again, the dominant factor is the increase in $\lambda$, and hence this flow also increases.

The movements between $N$ and the other states are slightly more subtle. To gain intuition into these movements we consider a simple heuristic example. In the example, the participation decision depends only on the idiosyncratic shock and takes the form of a threshold rule. To the extent that aggregate states and individual assets are slowly evolving in the true model, dynamics in idiosyncratic shocks dominate the movement of individuals between participation and non-participation, and this heuristic example offers some insight into the flows in Figure 2.

To examine the flows in the heuristic example, Consider Figure 3, which plots a singlepeaked density that we take to represent the invariant distribution of the idiosyncratic shocks. The two lines indicated on the figure represent the optimal decision rules in the good and 
bad states.

Figure 3: to Optimal decision rules in the heuristic example

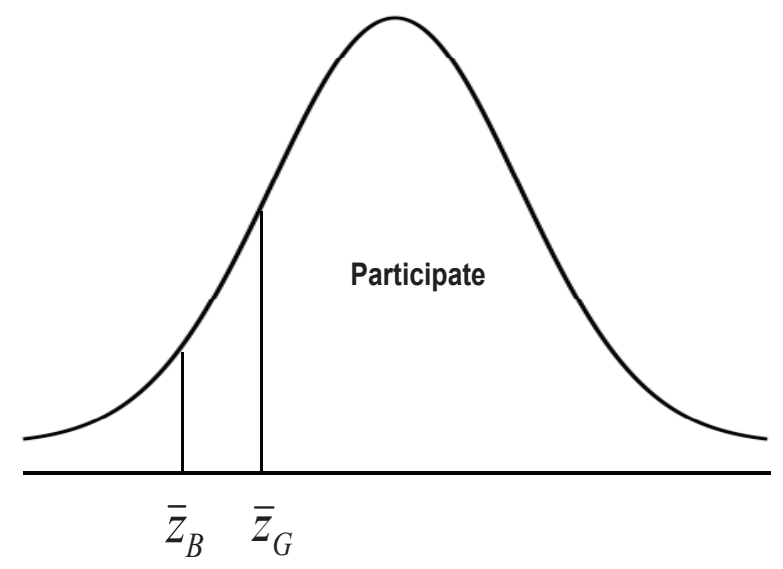

Consistent with Figure 1, the threshold for participation becomes higher when frictions are less severe. Mapping out the response of the various transition rates in this example following a switch in the aggregate state from bad to good can shed light on the patterns in Figure 2. Note that in Figure 2 there is a distinction between the long run effect and the effect in the initial period. This distinction is also present in the example. In the period in which the state changes from bad to good, all of the workers with idiosyncratic shocks between the two thresholds will move from in the labor force to out of the labor force. However, after the initial period, all movements into and out of the labor force are dictated solely by the movement of individuals across the threshold productivity.

We begin by focusing on the longer run changes. Loosely speaking, the movement of individuals across the boundary - in both directions - will be dictated by the mass of workers around the boundary. For the configuration shown in Figure 3, the density is increasing as we move from the lower threshold to the higher threshold, suggesting that these flows will increase. $^{12}$ If we had placed the thresholds on the other side of the peak in the density

\footnotetext{
${ }^{12}$ In the model there is also a "liquidity effect" at work-in recessions there are more nonemployed workers
} 
function, the implication would be reversed, but since in the true model the participation rate always exceeds fifty percent, the configuration shown in Figure 3 is the empirically relevant one.

If more individuals are crossing the boundary between participation and non-participation, both $E$ to $N$ and $U$ to $N$ flows will increase since this effect is at work independently of whether the individual is in $E$ or $U$. This long run effect is evident in Figure $2 .{ }^{13}$ The flow from out of the labor force into the labor force also increases, but now the change in $\lambda$ also influences the separate flows into the $E$ and $U$ destinations. Transitions from $N$ to $E$ occur when an individual both crosses the threshold and receives an employment opportunity. Since the probability of each of these increases as we move from the bad shock to the good shock, the $N$ to $E$ flow necessarily increases. For the $N$ to $U$ flow, these two effects move in opposite directions. It turns out that the effect due to the change in $\lambda$ is substantially larger than the change in the hazard of crossing the threshold, and as a result, the long run change in this flow is negative. Again, these effects are found in Figure 2.

Now we turn to analyzing the effects in the initial period in which the aggregate shock changes. In the initial period, the above effects will be augmented with a large one time flow out of the labor force that is associated with those individuals who lie in between the two thresholds. This induces an increase in both $E$ to $N$ and $U$ to $N$, which shows up in Figure 2 as a greater increase in both of these flows in the initial period relative to later periods. Because entry into the labor force in the initial period requires crossing a much that are close to the borrowing constraint, thus increasing their desire to work. As discussed below, the responses in Figure 2 suggest that this effect is relatively small.

${ }^{13}$ In fact, there is an additional, reinforcing effect. Although the change in the average productivity of the labor force is determined solely by the threshold productivity, a change in $\lambda$ influences the distribution of productivity within the employed and unemployed groups. Intuitively, as $\lambda$ increases, unemployment durations decrease and the unemployment pool is more heavily represented by the newly unemployed, who tend to be of lower productivity. The net effect is that the unemployment pool has a greater share of its workers close to the threshold, further increasing the $U$ to $N$ transition rate. 
higher threshold than in the previous period, there is a negative effect on the flows from out of the labor force in the initial period. Hence, the initial drop in the $N$ to $U$ flow is even more negative than the long run response. For the $N$ to $E$ flow, Figure 2 is consistent with the initial effect dominating the long run effect by a small amount, so that the net effect is a small decrease in the initial period, followed by a large increase thereafter. Note that for the most part the magnitudes of the flows change very little beyond the second period, suggesting that our heuristic device of ignoring the effects of changes in assets over time is not of first order importance.

Cyclical Properties of Flows Having analyzed the transition dynamics in detail, it is instructive to examine the business cycle statistics for the flows. They are reported in Table 5.

Table 5

\begin{tabular}{lcccccccccccc}
\hline \hline \multicolumn{10}{c}{ Cyclical Properties of Transition Rates: Model with Friction Shocks Only } \\
\hline \multicolumn{1}{c}{ Volatilities: $s t d(x)$} & \multicolumn{5}{c}{ Correlations: $\operatorname{corr}(x, Y)$} \\
\hline Data & $f_{E U}$ & $f_{E N}$ & $f_{U E}$ & $f_{U N}$ & $f_{N E}$ & $f_{N U}$ & $f_{E U}$ & $f_{E N}$ & $f_{U E}$ & $f_{U N}$ & $f_{N E}$ & $f_{N U}$ \\
Model & .085 & .032 & .077 & .060 & .043 & .064 & -.82 & .33 & .78 & .78 & .64 & -.70 \\
\hline \hline
\end{tabular}

By construction, the model matches the volatility of the transition rates $f_{E U}$ and $f_{U E}$. However, the model also seems to do a reasonable job of capturing the behavior of many of the other flows as well, both in terms of magnitude and correlation with output. Interestingly, although the participation rate in the model had the wrong correlation with output relative to the data, all of the underlying flows in the model have the same correlation with output as is found in the data. The reason that the participation rate ends up with the wrong correlation is apparently due to more subtle differences between the model and the data involving the relative magnitudes and correlations of the various flows. For example, the flow from $E$ to $N$ is both more volatile and displays a slightly higher correlation with output in the model 
than in the data.

Summary In summary, although the model with shocks only to frictions can generate substantial movements in unemployment, and captures many features of the transition rates, it generates changes in employment that are far too small, and changes in participation that are too large and of the wrong correlation with output. While the appeal of this type of specification is derived from the fact that researchers have examined it in settings with the participation rate exogenously fixed, we find that this assumption of constant participation is in fact inconsistent with the other features of the model when embedded into a setting that allows for an empirically reasonable labor supply response along the extensive margin.

\subsubsection{Results II: The Model With TFP Shocks Only}

In this subsection we consider the case in which the only shock is a shock to aggregate TFP. It is well known in the business cycle literature that this type of shock is capable of generating fluctuations in employment and the components of aggregate output that capture the key patterns found in the data. Our main objective here is to assess the ability of this case to match the additional facts that we documented in Section 2. While there is no presumption that this type of shock will work, we carry out this exercise because it is informative to understand the successes and failures of this model vis-a-vis the data.

Calibration of Shocks To proceed we consider a symmetric two-state Markov process on $Z$ with persistence parameter $\rho_{Z}$ and $Z$ taking values in the set $\left\{Z_{G}, Z_{B}\right\}$, where $Z_{G}=1+\varepsilon_{Z}$ and $Z_{B}=1-\varepsilon_{Z}$. To illustrate the effects of this type of shock we choose $\rho_{Z}=0.983$ to be consistent with much of the real business cycle literature. We choose $\varepsilon_{Z}$ to match the standard deviation of employment in the data. The resulting value is $\varepsilon_{Z}=0.0290$. 
Cyclical Properties of Stocks Panel B in Table 6 displays the cyclical properties for model generated data. For completeness, we include values from the data in Panel A.

Table 6

\begin{tabular}{cccccccccc}
\hline \hline \multicolumn{10}{c}{ Cyclical Properties of Labor Market Variables } \\
\hline \multicolumn{10}{c}{ A. Data } \\
\hline & $E$ & $u$ & lfpr & $f_{E U}$ & $f_{E N}$ & $f_{U E}$ & $f_{U N}$ & $f_{N E}$ & $f_{N U}$ \\
$\operatorname{std}(x)$ & .011 & .12 & .003 & .085 & .032 & .077 & .060 & .043 & .064 \\
$\operatorname{corrcoef}(x, Y)$ & .84 & -.87 & .46 & -.82 & .33 & .78 & .78 & .64 & -.70 \\
$\operatorname{corrcoef}\left(x, x_{-1}\right)$ & .92 & .92 & .72 & .73 & .20 & .84 & .73 & .41 & .75 \\
\hline & \multicolumn{10}{c}{ B. Model } & & & & & \\
\hline & $E$ & $u$ & $l f p r$ & $f_{E U}$ & $f_{E N}$ & $f_{U E}$ & $f_{U N}$ & $f_{N E}$ & $f_{N U}$ \\
$\operatorname{std}(x)$ & .011 & .03 & .010 & .028 & .053 & .012 & .051 & .034 & .034 \\
$\operatorname{corrcoef}(x, Y)$ & .95 & -.55 & .93 & .06 & -.28 & .01 & .04 & -.17 & -.19 \\
$\operatorname{corrcoef}\left(x, x_{-1}\right)$ & .76 & .39 & .72 & -.03 & .07 & -.11 & -.02 & -.13 & -.13 \\
\hline \hline
\end{tabular}

By construction, the model accounts for all of the fluctuations in employment in the data.

However, it fares poorly on the behavior of the two other stocks. First, although the model does capture the fact that the participation rate is procyclical and the unemployment rate is countercyclical, it misses on the relative volatility of the two by an order of magnitude. In fact, the standard deviation of the employment-to-population ratio is only slightly larger than that of the labor force participation rate, implying that virtually all of the fluctuations in employment are due to fluctuations in participation. One critique of standard real business cycle models with an operative extensive margin (e.g., Hansen (1985)) was that although they could generate substantial fluctuations in employment, they were silent on the issue of unemployment. By including frictions, our model does allow one to connect with data on unemployment, and perhaps not surprisingly, shows that when the only shocks to the model are to aggregate TFP, virtually none of the employment fluctuations show up as offsetting fluctuations in unemployment.

To gain more insight into the underlying economics, it is again instructive to examine how decision rules and flows are affected by the aggregate productivity shock. Figure 4 plots the 
behavior of the decision rule for participation that is equivalent to Figure 1 in the previous subsection.

Figure 4: Cut-off wealth and productivity levels for the model with TFP shocks only

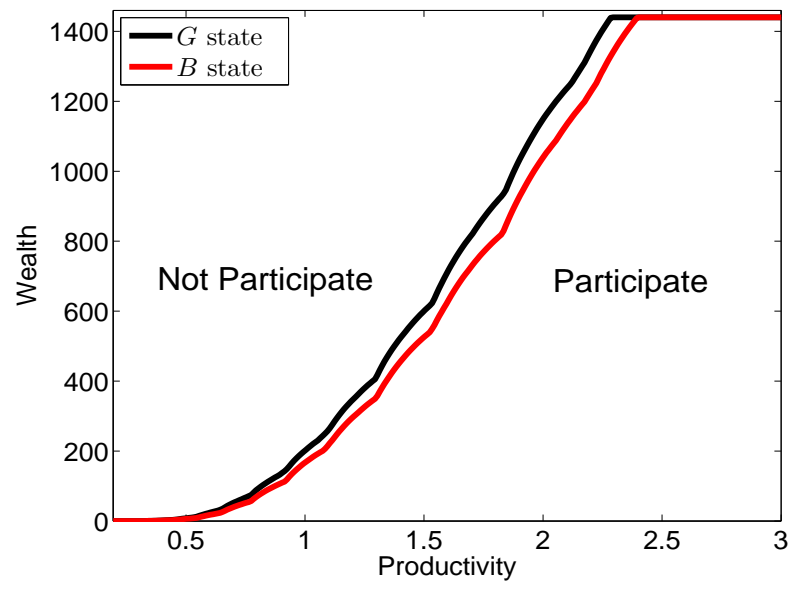

This figure illustrates the standard intertemporal substitution effects present in standard real business cycle models: when productivity is high individuals choose to work more, which corresponds to expanding the set of individual states in which they desire to work. This is the effect that leads to procyclical employment and participation. To the extent that the employment responses reflect standard intertemporal substitution, it may seem a curiosity that unemployment in this exercise does fluctuate countercyclically. We will be able to offer an explanation for this after we study transition dynamics in more detail.

Transition Dynamics Figure 5 shows how transition rates respond when the economy moves from a low aggregate productivity shock to a high one, and is computed in an analogous fashion to Figure 2.

Having analyzed the transition dynamics in the previous exercise in some detail, it is relatively easy to explain the patterns in Figure 5 with similar arguments. We start with the flows between $E$ and $U$. The figure shows that there is effectively no change in the $E$ 
Figure 5: Response of flows to a positive shock for the model with TFP shocks only
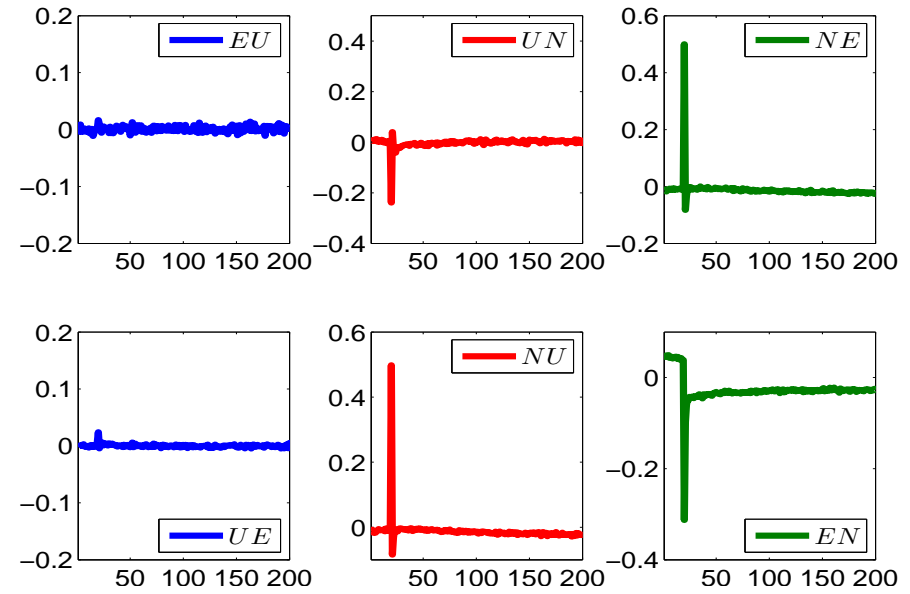

to $U$ and $U$ to $E$ transition rates. Consistent with our earlier analysis, these transitions are dominated by the frictional parameters $\lambda$ and $\sigma$, and since they are constant there is virtually no change in the transition rates.

Our previous heuristic example is again useful to understand the flows between $N$ and the other states. However, whereas a decrease in frictions led to a rightward movement of the threshold for participation, an increase in aggregate productivity leads to a leftward shift of the threshold, thereby reversing the implications. That is, there will now be fewer individuals who cross the threshold between participation and non-participation.

Again it is important to distinguish between changes in the period of the initial change in productivity versus the longer run change. By analogy with our earlier arguments, we now expect both the $E$ to $N$ and $U$ to $N$ flows to decrease in the long run. This is consistent with Figure 5, though note that the changes are quite small. ${ }^{14}$ Because the value of $\lambda$ is unchanged, we expect to see this same pattern for both the $N$ to $U$ and $N$ to $E$ flows, and this is indeed evident in Figure 5.

\footnotetext{
${ }^{14}$ In particular, note that the change in the $U$ to $N$ transition rate is much smaller in this case than in the case with friction shocks. As noted there, the threshold effect was augmented by an additional effect due to how changes in $\lambda$ affect the productivity distribution within the unemployment pool.
} 
Next consider the changes in transition rates during the initial period in which the aggregate productivity shock changes. Because the threshold moves to the left there will be a one time increase in participation associated with the entry of all those individuals with idiosyncratic shocks between the two threshold values. As a result, we expect to see an increase in both $N$ to $U$ and $N$ to $E$ transition rates on impact, and a decrease in both $E$ to $N$ and $U$ to $N$ transition rates. These patterns are also found in Figure 5.

Note that there is a slight bump in the $U$ to $E$ transition rate in the initial period. The movement in the threshold causes fewer unemployed people to leave the labor force in the initial period, increasing the overall rate at which these individuals transit into employment. Whereas this effect is also present beyond the initial period, the size of this effect is much larger in the initial period because it reflects the mass of workers in between the two thresholds and not just the movement of individuals across the threshold.

Having studied the behavior of the flows we are now in a position to address the countercyclical movement of the unemployment rate that was documented in Table 6. Given that frictions are constant, it may seem surprising that unemployment is countercyclical. The reason lies in the fact that there are now fewer flows into and out of the labor force, which therefore decreases the flow into the unemployment pool. Specifically, if employed individuals leave the labor force and later re-enter, they will typically experience a spell of unemployment. By decreasing the flow of individuals out of the labor force, this return flow is also reduced, thereby reducing one source of unemployment.

It is of interest to compare our findings from this exercise with the results in Veracierto (2008). Although Veracierto's model has predictions for the stocks of workers in the three labor market states, the gross flows are not uniquely determined due to the fact that in equilibrium many workers are necessarily indifferent between two transitions. However, we can 
compare predictions about the number of workers in each of the three states. While there are some differences in details regarding model specification, he also considers aggregate TFP shocks, and similar to us, he finds that although the model can generate substantial fluctuations in employment, it fares very poorly in accounting for the behavior of unemployment and participation. In particular, he finds that unemployment becomes procyclical. Veracierto ascribes the procyclical unemployment rate to the fact that when a high TFP shock occurs, individuals move from not-participating to participating, thereby increasing unemployment because it takes time to find a job. Figure 6 shows the dynamics in our model following an increase in $Z$ from $Z_{B}$ to $Z_{G}$ assuming that $Z$ remains at this level. The figure shows that our model has the same initial response to an increase in TFP as in Veracierto's model; that is, there is an immediate jump in the size of the labor force and an increase in unemployment. However, over time these individuals will become employed, and in our model the unemployment rate approaches a lower level than attained prior to the shock. This asymptotic response turns out to dominate the immediate effect in terms of its effect on the correlation between the unemployment rate and output. Hence, while our model does not match the volatility of the unemployment rate, it does produce a countercyclical unemployment rate. Despite this difference with the results in Veracierto, our model displays quantitative responses that are quite similar to his.

One difference between Veracierto's model and ours is that he assumes search is costly. Here we argue that this difference is not likely to be important. Consider an extension of our model in which a worker who is nonemployed has to exert some (indivisible) search effort in order to receive a job offer. If this search effort is costly, only some of the workers that we classify as being in $U$ would choose to exert job search effort. ${ }^{15}$ In the limit as the search

\footnotetext{
${ }^{15}$ Workers whom we identify as being in $N$ do not exert any effort since they prefer to stay nonemployed even without any search cost.
} 
Figure 6: Response of labor market stocks to a positive shock for the model with TFP shocks only
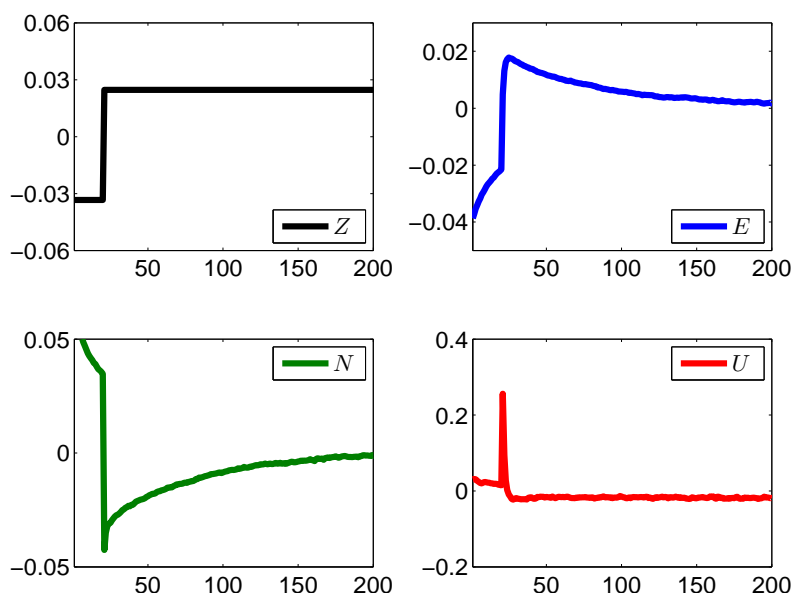

cost approaches zero, all workers that we categorize as being in $U$ would choose to exert job search effort. To the extent that search costs are relatively low, we therefore do not believe that adding search costs would overturn our findings.

More generally, another piece of intuition in the literature is that if search effort and the ease of finding a job are complements, and if unemployment is the activity of search, then unemployment should be procyclical. Shimer (2004) questions the assumption that search effort and the ease of finding a job are complements. Moreover, assuming a small but strictly positive search cost, our analysis in this and the previous subsection suggests that search effort among the non-employed can either increase or decrease over the cycle, depending upon the nature of the shock causing the cycle. We believe that one reason for the presumption that search effort is complementary with the ease of finding a job is that much of the search literature assumes linear utility and hence no income efffects. The fact that search intensity can be countercylical in our model is related to income effects: holding search intensity fixed, if it is harder to find a job then expected income decreases, leading to 
greater search effort to maintain consumption. ${ }^{16}$

Whether nonemployed workers search harder during recessions is ultimately an empirical issue. Recent work suggests that if anything, search intensity may be countercyclical. For example, Shimer (2004) examines several indicators of aggregate search intensity over time. One of his indicators, the number of search methods used by attached workers, increased during 2001 (his Figure 4). A similar pattern holds even when the sample is limited to active job searchers (see his Figure 7). For earlier periods this measure of search intensity does not exhibit a strong cyclical pattern, but it does always increase during recessionary periods (see his Figure 8).

In summary, we think our main findings are robust to the incorporation of small search costs. While we think it is of interest to extend our analysis to allow for endogenous search intensity, we also think additional empirical work on search intensity is required in order to guide the development of these theories.

Cyclical Properties of Flows Having looked at how the transition rates respond, we now return to the cyclical behavior of the transition rates in Table 6. If one were to only look at the standard deviations one might conclude that the model is doing a reasonable job in capturing some of the fluctuations. But when one looks at the correlations with output and the autocorrelations it is apparent that the model is capturing virtually none of the dynamics that is present in the flows in the data. The reason for the failure along this dimension is that productivity shocks lead to almost no persistent change in transition rates. That is, almost all of the fluctuations in transition rates are due to the effects that take place in the period

\footnotetext{
${ }^{16}$ Shimer (2004) questions the assumption that search effort and the ease of finding a job are complements and he argues that it is plausible to have a modified view of job search effort where some workers respond to deterioriating labor market conditions by increasing their search intensity. He then constructs a model where search intensity can be countercyclical.
} 
of the impact. This is in contrast to the case with friction shocks only, where we found much larger and persistent changes in the $E U, U E, N U$, and $N E$ flows.

\subsection{Results III: Shocks to TFP and Frictions-The Benchmark}

A very simple characterization of the findings from our first two exercises is that a model with shocks to frictions can do a reasonable job of accounting for the behavior of unemployment and many of the transition rates, whereas a model with shocks to TFP can do a reasonable of accounting for the behavior of employment. Neither model seems capable of accounting for the behavior of participation, since in both cases participation seems to fluctuate too much. However, it is interesting to note that although in both cases the participation rate fluctuates too much, in the case of TFP shocks it is procyclical whereas in the case of friction shocks it is countercyclical. Noting these results, it seems possible that a model that features shocks to both frictions and TFP could do a reasonable job of accounting for a large set of the labor market facts. In this section we show this to be the case.

Calibration of Shocks As before, we assume that $Z, \lambda$, and $\sigma$ all follow symmetric twostate Markov processes, and we keep the same notation in terms of denoting good and bad states. Once again, for ease of exposition, we focus on the case in which the shocks are all perfectly correlated, so that only two realizations can occur: either all values are good or all values are bad. Our main goal is to show that this type of specification can capture many of the facts from Section 2. We set $\rho_{Z}=0.983$ similar to above. $\varepsilon_{Z}$ is calibrated to 0.0287 to match the standard deviation of employment in the data. We choose the volatility of the two transition rates between employment and unemployment so that their standard deviations are the same as in the data. The calibrated values for the shock processes are $\left(\lambda_{G}, \lambda_{B}\right)=(0.509,0.371)$ and $\left(\sigma_{G}, \sigma_{B}\right)=(0.01249,0.01351)$. 
Cyclical Properties of Stocks Table 7 shows the results for the cyclical behavior of employment, the unemployment rate and the participation rate.

Table 7

\begin{tabular}{cccc|ccc}
\hline \hline \multicolumn{6}{c}{ Behavior of Stocks with TFP and Friction Shocks } \\
\hline \multicolumn{4}{c}{ Volatilities: } & std $(x)$ & \multicolumn{4}{c}{ Correlations: } & $\operatorname{corr}(x, Y)$ \\
\hline Data & $u$ & lfpr & $E$ & $u$ & lfpr & $E$ \\
Model & .12 & .003 & .011 & -.87 & .46 & .84 \\
\hline \hline
\end{tabular}

While the volatility of employment in the model is the same as that in the data by construction, the model also does a good job of accounting for the size of fluctuations in both unemployment and participation. Additionally, it also correctly accounts for the fact that employment is strongly procyclical, the unemployment rate is strongly countercyclical, and the labor force participation rate is weakly procyclical. We noted previously that in each of the first two exercises, the participation rate fluctuated too much. However, because the two shocks move participation in opposite directions, when both shocks are present the overall effect on participation is much smaller than the individual effects. The cyclicality of the participation rate is dependent on the relative magnitudes of the shocks. Figure 7 once again shows the behavior of the decision rule for participation in the good and bad states.

Figure 7: Cut-off wealth and productivity levels for the benchmark model

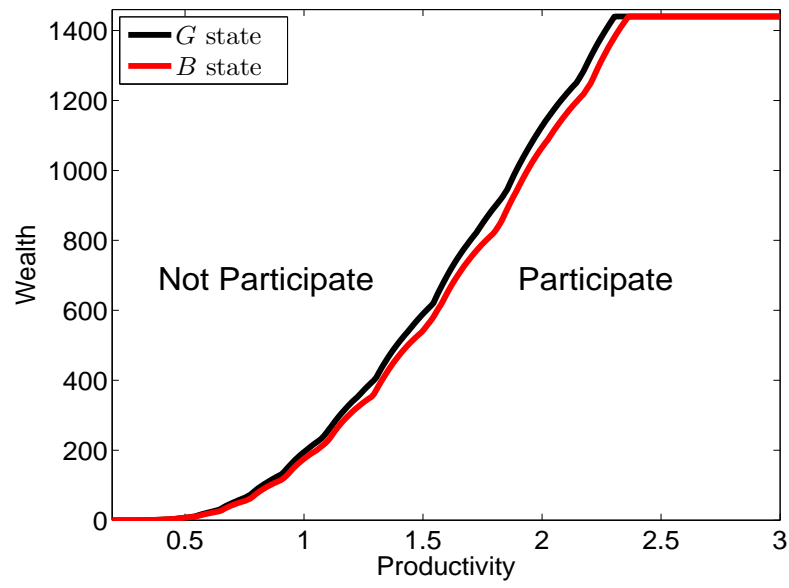


This figure indicates that for the parameterization in this exercise, individuals increase their desire to participate in good times, though the increase is smaller than what was observed for the case of aggregate productivity shocks only, as shown in Figure 4. While the sign of the net effect on participation is obviously dependent on parameter values, we do want to emphasize that a robust feature of this specification is that the participation rate will exhibit much less cyclicality than either employment or the unemployment rate.

In addition to making predictions about the cyclicality of the number of individuals unemployed, our model also has interesting implications for the mix of individuals that are unemployed and how it varies over the cycle. An issue that has recently received attention is how the average quality of unemployed workers changes over the business cycle. Mueller (2010), for example, finds that the average quality of the unemployed is countercyclical and suggests that this is a useful diagnostic for evaluating theories of unemployment. The average value for idiosyncratic productivity among unemployed workers in our model is countercyclical, consistent with the evidence in Mueller.

Transition Dynamics Figure 8 again shows the responses of the transition rates as the economy moves from bad times to good times, analogously to what we previously showed in Figures 2 and 5.

We will not discuss these responses in detail, but note that they are effectively a convex combination of the results previously shown for the two shocks individually and hence do not present any novel effects relative to the earlier analysis.

Cyclical Properties of Flows Table 8 shows the results for the transition probabilities. This table shows that the model does a good job of accounting for the key patterns. The model captures the countercyclicality of unemployment inflows ( $E U$ and $N U$ flow rates), 
Figure 8: Response of flows to a positive shock for the benchmark model
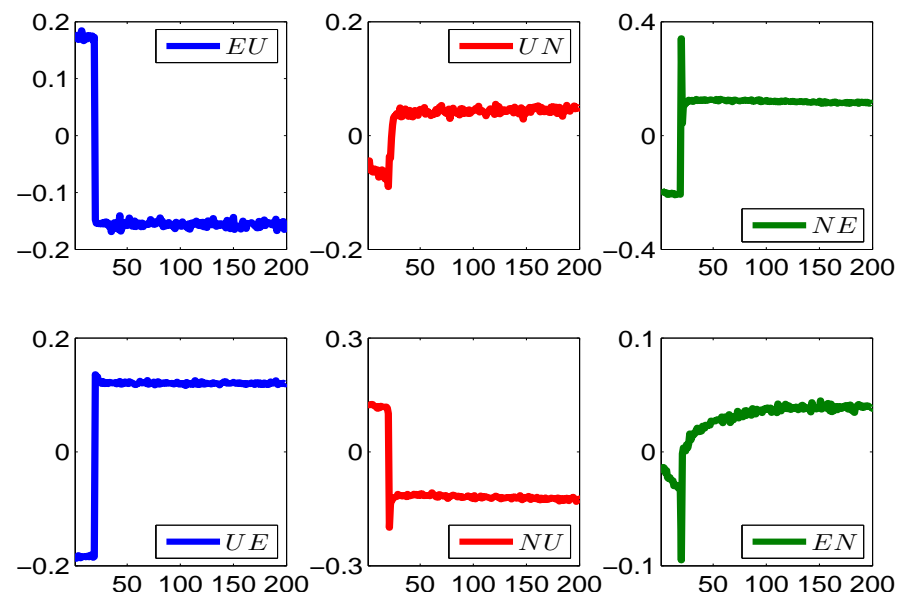

procylicality of unemployment outflows ( $U E$ and $N U$ flow rates) and mild procyclicality of the $E N$ flow rate. The model delivers a volatility and correlation (with output) for $f_{N E}$ that are somewhat too high.

Table 8

\begin{tabular}{|c|c|c|c|c|c|c|}
\hline \multicolumn{7}{|c|}{ Flows in the Model with TFP Shocks and Friction Shocks } \\
\hline \multicolumn{7}{|c|}{ A. Data } \\
\hline & $f_{E U}$ & $f_{E N}$ & $f_{U E}$ & $f_{U N}$ & $f_{N E}$ & $f_{N U}$ \\
\hline $\operatorname{std}(x)$ & .085 & .032 & .077 & .060 & .043 & .064 \\
\hline $\operatorname{corrcoef}(x, Y)$ & -.82 & .33 & .78 & .78 & .64 & -.70 \\
\hline $\operatorname{corrcoef}\left(x, x_{-1}\right)$ & .73 & .20 & .84 & .73 & .41 & .75 \\
\hline \multicolumn{7}{|c|}{ B. Model } \\
\hline & $f_{E U}$ & $f_{E N}$ & $f_{U E}$ & $f_{U N}$ & $f_{N E}$ & $f_{N U}$ \\
\hline $\operatorname{std}(x)$ & .085 & .031 & .077 & .051 & .080 & .066 \\
\hline $\operatorname{corr}(x, Y)$ & -.90 & .35 & .92 & .56 & .89 & -.92 \\
\hline $\operatorname{corr}\left(x, x_{-1}\right)$ & .68 & .09 & .72 & .30 & .70 & .68 \\
\hline
\end{tabular}

Decompositions Given that the above specification does a reasonable job of accounting for the cyclical fluctuations of the labor market variables, it is of interest to decompose the fluctuations in various series into the parts attributable to each of the three shocks: $Z, \lambda$, and $\sigma$. To do this we simply recompute the model assuming that two of the three shocks are shut down. Table 9 does this for the three aggregates. It also reports the correlations of the 
variables with output for each specification.

Table 9

\begin{tabular}{lcccc|ccc}
\hline \hline \multicolumn{8}{c}{ Contribution of the Shocks: Stocks } \\
\hline \multicolumn{4}{c}{ Volatilities: $\operatorname{std}(x)$} & \multicolumn{3}{c}{ Correlations: } & $\operatorname{corr}(x, Y)$ \\
\hline Data & $Y$ & $u$ & lfpr & $E$ & $u$ & lfpr & $E$ \\
All & .016 & .12 & .003 & .011 & -.87 & .46 & .84 \\
$Z$ & .020 & .13 & .004 & .011 & -.98 & .56 & .95 \\
$\lambda$ & .018 & .03 & .010 & .011 & -.55 & .93 & .95 \\
$\sigma$ & .001 & .10 & .007 & .002 & -.89 & -.77 & .42 \\
\hline \hline & .000 & .01 & .001 & .001 & -.33 & -.16 & .07 \\
\hline \hline
\end{tabular}

Several results are notable. First, consistently with our earlier results, the shocks to $\lambda$ are the quantitatively most important ones for the fluctuations in the unemployment rate whereas the fluctuations in $Z$ are the most important ones for the fluctuations in employment. Note that allowing for fluctuations in frictions does not diminish the role that TFP shocks play in accounting for fluctuations in employment. From the perspective of employment fluctuations the model looks very much like the model that has only TFP shocks. The key effect of frictions vis-a-vis employment fluctuations is that they change the participation dynamics so that unemployment fluctuations are now much closer to being the mirror image of employment fluctuations.

Fluctuations in $\sigma$ are relatively unimportant for all three stocks. It may seem somewhat surprising that shocks to $\sigma$ are so unimportant given that the transition rates between $E$ and $U$ fluctuate by roughly the same amount. To obtain some insight into this Table 10 carries out the same exercise for the two transition rates between $E$ and $U$. 
Table 10

\begin{tabular}{lcc|cc}
\hline \hline \multicolumn{3}{c}{ Contribution of the Shocks: Flows } \\
\hline & \multicolumn{2}{c|}{$s t d(x)$} & \multicolumn{2}{c}{ corrcoef $(x, Y)$} \\
\hline \multirow{3}{*}{ Data } & $f_{E U}$ & $f_{U E}$ & $f_{E U}$ & $f_{U E}$ \\
All & .085 & .077 & -.82 & .78 \\
$z$ & .085 & .077 & -.90 & .92 \\
$\lambda$ & .027 & .012 & .04 & -.01 \\
$\sigma$ & .069 & .076 & -.67 & .74 \\
$\sigma$ & .033 & .011 & -.49 & -.05 \\
\hline \hline
\end{tabular}

An interesting result here is that even when there are only shocks to $\lambda$ so that $\sigma$ is constant, the model accounts for roughly $80 \%$ of the volatility in $f_{E U}$. This is because we allow individuals to receive an employment opportunity in the same period that they experience an employment separation shock. It follows that the likelihood of an $E$ to $U$ flow is affected by the value of $\lambda$. To see why this is, note that when $\lambda$ is low it is more likely that a worker who experiences an employment separation will remain in the unemployment state. This phenomenon in the model captures an important feature that is present in the actual data. That is, in the household survey, an individual who transits from employment to unemployment after an interview date, but who receives a job offer and starts to work prior to the next interview date will be recorded as an $E$ to $E$ flow. The higher is the job offer arrival rate, the greater is the chance that this worker will be recorded as an $E$ to $E$ transition. ${ }^{17}$

Note that in the model with only shocks to $\sigma$ there is also an effect on the transition rate from $U$ to $E$. This may at first seem somewhat surprising. However, this effect is due to a one-time effect associated with changes in the value of $\sigma$. The nature of the effect is that during good times (i.e., when $\sigma$ decreases), some people move from participation to non-participation due to the fact that as it becomes easier to work when one desires, one

\footnotetext{
${ }^{17}$ As an alternative exercise we could ask what types of fluctuations result if we assumed that there were only shocks to $\sigma$ but that the size of these shocks were sufficient to match the volatility in $f_{E U}$.
} 
becomes more particular about timing periods of work with high values of the idiosyncratic shocks. As a result, during the period in which $\sigma$ changes from high to low, some of the previously unemployed move to non-participation and hence even though they receive employment opportunities they choose not to work. This causes a one-time reduction in $f_{U E}$. The fact that it is a one-time reduction is evident in the very low correlation between $f_{U E}$ and output in the case of shocks only to $\sigma$.

\section{Conclusion}

We have developed a general equilibrium model of gross worker flows and used it to study the role of various shocks in accounting for business cycle fluctuations in the labor market. A key message from our analysis is that our model offers important insights into the forces that drive business cycle fluctuations in the labor market. In contrast to the implications of standard two-state models that stress matching frictions, we find that fluctuations in employment loss and employment offer rates are unable to account for the key patterns in labor market variables over the business cycle unless they are combined with a cyclical shock to the return to market activity. We find that a model that features both these drivers of fluctuations is able to account for the main features not only of labor market aggregates but also of gross worker flows.

Our model offers a rich description of individual labor supply in a setting with heterogeneity, search frictions and an empirically reasonable market structure. It is the first paper to consider the effects of aggregate shocks on individual labor market transitions in this setting. However, it is also simplistic in some dimensions relevant for the microeconomic data. One of these dimensions regards our model of the household as an infinitely-lived unit. Clearly, an extension that distinguishes different members of the households would be relevant, as would 
an age dimension. Also, we have left out details of job experiences, including any specifics of what influences individual productivity (such as learning on the job and on-the-job search). Similarly, we abstract from an explicit consideration of search costs. We do believe that our framework is a very useful starting point for extensions in all these directions. Related, we also believe that it is useful for assessing a variety of further issues, such as the heterogeneous effects of business cycles on various subgroups of the population. While we have focused on aggregate shocks to frictions and the return to market activity, we can also study other aggregate shocks, including various candidates for demand shocks.

Finally, as pointed out above, in contrast with much of the literature - in particular the recent studies of Hall (2005) and Shimer (2005) — we leave open what the deeper explanations for the fluctuations in labor market frictions might be, as we leave open what drives the returns to market activity and any connections between these shocks. The good performance of the model of course makes it all the more important to further isolate and study these drivers. One view in the literature is that a search/matching model with rigid wage formation and frictions that are entirely driven by productivity fluctuations can explain the data well. From the present perspective, such a model will likely be hard to square with labor market flows, since we have found the movements in the return to market activity necessary for understanding them. 


\section{References}

[1] Blanchard, O., and P. Diamond, "The Cyclical Behavior of the Gross Flows of U.S. Workers," Brookings Papers on Economic Activity 1990, 85-155.

[2] Chang, Y., and S. Kim., "From Individual to Aggregate Labor Supply: A Quantitative Analysis Based on a Heterogeneous Agent Macroeconomy," International Economic Review 47 (2006), 1-27.

[3] Christiano, L.J., M. Trabandt, and K. Walentin, "Involuntary Unemployment and the Business Cycle," (2010), mimeo.

[4] Galí, J., F. Smets, and R. Wouters, "Unemployment in an Estimated New Keynesian Model," mimeo, 2011.

[5] Garibaldi, P. and E. Wasmer, "Equilibrium Search Unemployment, Endogenous Participation, and Labor Market Flows," Journal of European Economic Association 3 (2005), 851-882.

[6] Haefke, C., and M. Reiter, "What Do Participation Fluctuations Tell Us About Labor Supply Elasticities?," Mimeo, IZA, 2011.

[7] Hall, R., "Employment Fluctuations with Equilibrium Wage Stickiness," American Economic Review 95 (2005), 50-65.

[8] ______, "Cyclical Movements along the Labor Supply Function," in K. Bradbury, C. L. Foote, R. K. Triest, (eds.) Labor Supply in the New Century, Federal Reserve Bank of Boston, (2008), 241-278. 
[9] ______, "Reconciling Cyclical Movements in the Marginal Value of Time and the Marginal Product of Labor," Journal of Political Economy 117 (2009), 282-323.

[10] Hansen, G.D., "Indivisible Labor and the Business Cycle," Journal of Monetary Economics 16, (1985), 309-337.

[11] Krusell, P., T. Mukoyama, R. Rogerson, and A. Şahin, "Aggregate Labor Market Outcomes: The Role of Choice and Chance," Quantitative Economics 1 (2010), 97-128.

$[12]$ "A Three State Model of Worker Flows in General Equilibrium," Journal of Economic Theory 146 (2011), 1107-1133.

[13] Krusell, P., T. Mukoyama, and A. Şahin, "Labor-Market Matching with Precautionary Savings and Aggregate Fluctuations," Review of Economic Studies 77:4, pp. 1477-1507.

[14] Krusell, P., and A. Smith Jr., "Income and Wealth Heterogeneity in the Macroeconomy," Journal of Political Economy 106 (1998), 867-896.

[15] Kydland, F., and E. Prescott, "Time to Build and Aggregate Fluctuations," Econometrica 50 (1982), 1345-70.

[16] Lucas, R.E., and L. Rapping, "Intertemporal Substitution of Leisure in the Theory of Labor Supply,” Journal of Political Economy 77 (1969), 721-754.

[17] Mueller, A., "Separations, Sorting and Cyclical Unemployment," mimeo, Columbia University, 2010.

[18] Poterba, J., and L. Summers, "Reporting Errors and Labor Market Dynamics," Econometrica 54 (1986), 1319-1338. 
[19] Rogerson, R. and R. Shimer, "Search in Macroeconomic Models of the Labor Market," Handbook of Labor Economics, Volume 4A, edited by Orley Ashelfelter and David Card, (2010), 619-700.

[20] Shimer, R., "Search Intensity," (2004), mimeo, University of Chicago.

[21] Shimer, R., "The Cyclical Behavior of Equilibrium Unemployment and Vacancies," American Economic Review, 95:1 (2005), pp. 25-49.

[22] Shimer, R., "Job Search, Labor Force Participation, and Wage Rigidities," (2011), mimeo, University of Chicago.

[23] Tripier, F., "Can the Labor Market Search Model Explain the Fluctuations of Allocations of Time?," Economic Modelling 21 (2004), 131-146.

[24] Veracierto, M., "On the Cyclical Behavior of Employment, Unemployment and Labor Force Participation," Journal of Monetary Economics, 55 (2008), 1143-1157. 


\section{Appendix}

\section{A.1 Data}

The Current Population Survey (CPS) reports the labor market status of the respondents each month that allows the BLS to compute important labor market statistics like the unemployment rate. In particular, in any given month a civilian can be in one of three labor force states: employed $(E)$, unemployed $(U)$, and not in the labor force $(N)$. The BLS definitions for the three labor market states are as follows:

- An individual is counted as employed if he or she did any work at all for pay or profit during the survey month. This includes part-time or temporary work as well as full-time year-round employment.

- An individual is considered unemployed if he or she does not have a job, has actively looked for employment in the past 4 weeks and is currently available to work.

- An individual is classified as not in the labor force if he or she is included in the labor force population universe (older than 16 years old, non-military, noninstitutionalized) but are neither employed nor unemployed.

Households are interviewed for four consecutive months, rotate out for eight months and then rotate in for another four months. The panel feature of the CPS makes it possible to calculate transitions by individual workers between these three labor market states. However, not all the respondents stay in the sample for consecutive months; the rotating feature of the panel implies that only 75 percent are reinterviewed according to the CPS sampling design. Moreover, many other respondents cannot be found in the consecutive month due to various reasons and are reported as missing. The failure to match individuals in consecutive months is known as margin error and it causes biased estimates of the flow rates as discussed by 
Abowd and Zellner (1985), Fujita and Ramey (2009), and Poterba and Summers (1986). The simplest correction for margin error is to simply drop the missing observations and reweight the transitions that are measured, a procedure that is known as the missing-at-random (MAR) method. However, this procedure could lead to biases if missing observations are not missing at random. To deal with this problem, Abowd and Zellner (1985) and Poterba and Summers (1986) proposed alternative corrections for margin error which use information on labor market stocks. Their correction reweights the unadjusted flows in order to minimizes the distance between the reported labor market stocks and the stocks that are imputed from the labor market transitions. We follow the algorithm proposed by Elsby, Hobijn, and Şahin (2011), which is similar in spirit to Poterba and Summers' method, but differs in implementation. We use the basic monthly CPS files from January 1976 to December 2009 and data from January 1968 to December 1975 based on tabulations by Joe Ritter using data that was made available by Hoyt Bleakley. All transition probabilities are calculated for the population older than 16 years old and are seasonally adjusted.

\section{References}

[1] Abowd, J., and A. Zellner, "Estimating Gross Labor-Force Flows," Journal of Business and Economic Statistics 3 (1985), 254-283.

[2] Elsby, M., Hobijn B. and A. Şahin, "The Participation Margin and Cyclical Unemployment Fluctuations," mimeo.

[3] Fujita, S., and G. Ramey, "The Cyclicality of Separation and Job Finding Rates," International Economic Review 2 (2009), 415-430. 


\section{A.2 Calibration of the Steady State}

There is strong evidence in the literature (see, e.g., Poterba and Summers (1986)) that classification errors lead to spurious flows, especially between unemployment and not in the labor force. To capture this we will also add a measurement equation to our model. To facilitate exposition we will calibrate the model assuming no classification error and then show how the model's implications are affected when we add this type of error.

The steady state model has nine parameters that need to be assigned: preference parameters $\beta$ and $\alpha$, production parameters $\theta$ and $\delta$, idiosyncratic shock parameters $\rho_{z}$ and $\sigma_{\varepsilon_{z}}$, frictional parameters $\sigma$ and $\lambda$, and the tax rate $\tau$. Because data on labor market transitions are available monthly, we set the length of a period to be one month. We set $\tau=.30{ }^{18}$ Because our model is a variation of the standard growth model, we can assign some parameter values following standard procedures used to calibrate versions of the growth model. Because of incomplete markets and idiosyncratic uncertainty, we cannot derive analytic expressions for the steady state, and so cannot isolate the connection between certain parameters and target values. Nonetheless, it is still useful and intuitive to associate particular targets and parameter values. Specifically, given values for $\lambda, \sigma, \rho_{z}$, and $\sigma_{\varepsilon_{z}}$, we choose $\theta=.3$ to target a capital share of $.3, \delta$ to achieve an investment to output ratio equal to .2 , and the discount factor $\beta$ to target an annual real rate of return on capital equal to $4 \%$. The other preference parameter $\alpha$, which captures the disutility of working, is set so that the steady state value of the employment to population ratio is equal to .61. This is the value of the employment to population ratio for the population aged 16 and older for the period $1968-2009 .{ }^{19}$

\footnotetext{
${ }^{18}$ Following the work of Mendoza et al. (1994) there are several papers which produce estimates of the average effective tax rate on labor income across countries. Minor variations in methods across these studies produce small differences in the estimates, but .30 is representative of these estimates.

${ }^{19}$ We calibrate to values for the period 1968-2009 because this is the period for which we have consistent measures of labor market flows.
} 
It remains to choose values for $\lambda, \sigma, \rho_{z}$ and $\sigma_{\varepsilon_{z}}$. Recall that our idiosyncratic shock process should be viewed as a composite of all idiosyncratic shocks that affect the static return to working versus not working. Shocks to wages are of course only one such component. However, since these are the shocks that we have the best measures of, our benchmark specification calibrates the shock process based on estimates of idiosyncratic wage shocks. Specifically, we choose values for $\rho_{z}$ and $\sigma_{\varepsilon}$ based on Floden and Linde (2001), who estimated $\rho_{z}=.92$ and $\sigma_{\varepsilon}=.21$ expressed on an annual basis. ${ }^{20}$ There is an intimate connection between $\lambda$ and the unemployment rate in the model. If $\lambda=1$ then unemployment will be zero, since everyone always has the opportunity to work. We therefore choose $\lambda$ so that the steady state unemployment rate matches the average value for the unemployment rate in the US data for the period $1968-2009$, which is .061 . We choose $\sigma$ to target the average flow rate out of employment over our sample period, which is $3.6 \%$. We target this rate based on our belief that the employment state is the one subject to the least amount of measurement error.

The labor market flows in our calibrated model and the data are displayed in Table A1.

Table A.1

\begin{tabular}{cccc|cccc}
\hline \hline \multicolumn{4}{c}{ Flows in the Data and the Model } \\
\hline \multicolumn{3}{c}{ US 1968-2009 } & \multicolumn{5}{c}{ Model } \\
\hline FROM & \multicolumn{3}{c}{ TO } & FROM & \multicolumn{3}{c}{ TO } \\
& $E$ & $U$ & $N$ & & $E$ & $U$ & $N$ \\
$E$ & 0.954 & 0.016 & 0.030 & $E$ & 0.954 & 0.007 & 0.039 \\
$U$ & 0.270 & 0.508 & 0.222 & $U$ & 0.396 & 0.505 & 0.099 \\
$N$ & 0.048 & 0.027 & 0.925 & $N$ & 0.035 & 0.044 & 0.921 \\
\hline \hline
\end{tabular}

Overall the model does a reasonable job of capturing the salient features of the data.

\footnotetext{
${ }^{20}$ Krusell et al. (2011) showed that the ability of the model to account for the flows between states remains relatively unchanged over a wide range of values of $\rho$ and $\sigma_{\varepsilon}$. What mattered most was that $\rho$ was reasonably persistent (at least .5), but not too close to being a unit root (say less than .97), and that $\sigma_{\varepsilon}$ was not too small. An issue for our quantitative exercises is the extent to which different specifications of the shock process influence our results, despite having little impact on worker flows. We carry out sensitivity analysis to assess this.
} 
Specifically, it does a good job of capturing the degree of persistence in each of the three states. One major discrepancy is that the model does not generate enough flows from $U$ to $N$. Given our strategy of targeting the stock of workers in $U$, this necessarily implies that the other flow out of $U$ (i.e., the flow from $U$ to $E$ ) must also be off. Classification error is discussed in Appendix A.3.

\section{References}

[1] Floden, M., and J. Linde, "Idiosyncratic Risk in the United States and Sweden: Is There a Role for Government Insurance?," Review of Economic Dynamics 4 (2001), 406-437.

[2] Mendoza, E., A. Razin, and L. Tesar, "Effective Tax Rates in Macroeconomics: CrossCountry Estimates of Tax Rates on Factor Incomes and Consumption," Journal of Monetary Economics 34 (1994), 297-323.

\section{A.3 Classification Error}

As discussed in Section 4.1, there is strong evidence that classification errors lead to spurious flows. In this section, we allow classification errors to induce spurious transitions between $U$ and $N$ and examine how our results are affected. In particular, following the estimates of Poterba and Summers (1986), we assume that a consumer with true state $U$ state misreports it as $N$ with probability 0.1146 and that a consumer with true state $N$ state misreports it as $U$ state with probability $0.0064 .^{21}$ We recalibrate the model, setting $\alpha, \lambda$, and $\sigma$ in order to match the observed employment population ratio of .61, the average value of unemployment rate of .061 , and the average flow rate out of employment of $3.6 \%$. The new parameter values are $\alpha=0.606, \lambda=0.423, \sigma=0.0135$.

\footnotetext{
${ }^{21}$ Although Poterba and Summers (1981) also describe the classification errors for other combinations of the states, here we focus only on $U$ and $N$.
} 
Table A.2

\begin{tabular}{cccc|cccc}
\hline \hline \multicolumn{3}{c}{ Flows in the Data and the Model with Classification Error } \\
\hline \multicolumn{3}{c}{ US 1968-2009 } & \multicolumn{5}{c}{ Model } \\
\hline FROM & \multicolumn{3}{c|}{ TO } & FROM & \multicolumn{3}{c}{ TO } \\
& $E$ & $U$ & $N$ & & $E$ & $U$ & $N$ \\
$E$ & 0.954 & 0.016 & 0.030 & $E$ & 0.954 & 0.007 & 0.039 \\
$U$ & 0.270 & 0.508 & 0.222 & $U$ & 0.363 & 0.439 & 0.199 \\
$N$ & 0.048 & 0.027 & 0.925 & $N$ & 0.038 & 0.052 & 0.910 \\
\hline \hline
\end{tabular}

Steady state flows are presented in Table A.2. Comparing with Table A.1, the $U E$ transition rate goes down slightly, resulting in a slightly better match with data. The $U N$ transition rate increases substantially and is almost as high as in the data. The match of the $U U$ transition rate somewhat worsens.

With this new set of parameter values, we repeat the exercise for our benchmark model, recalibrating the parameters of the driving forces to match the same targets as in the main text (the standard deviation of employment, the standard deviation of the $E U$ flow rate, the standard deviation of the $U E$ flow rate). The new parameter values are: $\varepsilon_{Z}=0.02895$, $\left(\lambda_{G}, \lambda_{B}\right)=(0.4937,0.3523)$, and $\left(\sigma_{G}, \sigma_{B}\right)=(0.01289,0.01411)$. Table A.3 presents the results.

Table A.3

\begin{tabular}{lccc|ccc}
\hline \hline \multicolumn{6}{c}{ Behavior of Stocks with TFP and Friction Shocks } \\
\hline & \multicolumn{4}{c}{ Volatilities: } & std $(x)$ & \multicolumn{3}{c}{ Correlations: } & $\operatorname{corr}(x, Y)$ \\
\hline \multirow{2}{*}{ Data } & $u$ & $l f p r$ & $E$ & $u$ & lfpr & $E$ \\
Model (Benchmark) & .12 & .003 & .011 & -.87 & .46 & .84 \\
Model (CE) & .13 & .004 & .011 & -.98 & .56 & .97 \\
\hline \hline
\end{tabular}

The row labelled Model (Benchmark) simply repeats Table 7 from the paper. The row labelled Model (CE) is the model that incorporates classification error. The results from the new exercise are almost identical to the benchmark result, except that the cyclicality of the labor force participation rate is slightly weaker.

Table A.4 describes the cyclical properties of the flows. 
Table A.4

\begin{tabular}{|c|c|c|c|c|c|c|}
\hline \multicolumn{7}{|c|}{ Flows in the Benchmark and CE Models } \\
\hline \multicolumn{7}{|c|}{ A. Data } \\
\hline & $f_{E U}$ & $f_{E N}$ & $f_{U E}$ & $f_{U N}$ & $f_{N E}$ & $f_{N U}$ \\
\hline $\operatorname{std}(x)$ & .085 & .032 & .077 & .060 & .043 & .064 \\
\hline $\operatorname{corrcoef}(x, Y)$ & -.82 & .33 & .78 & .78 & .64 & -.70 \\
\hline $\operatorname{corrcoef}\left(x, x_{-1}\right)$ & .73 & .20 & .84 & .73 & .41 & .75 \\
\hline \multicolumn{7}{|c|}{ B. Model (Benchmark) } \\
\hline & $f_{E U}$ & $f_{E N}$ & $f_{U E}$ & $f_{U N}$ & $f_{N E}$ & $f_{N U}$ \\
\hline $\operatorname{std}(x)$ & .085 & .031 & .077 & .051 & .080 & .066 \\
\hline $\operatorname{corr}(x, Y)$ & -.90 & .36 & .92 & .56 & .89 & -.92 \\
\hline $\operatorname{corr}\left(x, x_{-1}\right)$ & .68 & .09 & .72 & .30 & .70 & .68 \\
\hline \multicolumn{7}{|c|}{ B. Model (Classification Error) } \\
\hline & $f_{E U}$ & $f_{E N}$ & $f_{U E}$ & $f_{U N}$ & $f_{N E}$ & $f_{N U}$ \\
\hline $\operatorname{std}(x)$ & .088 & .030 & .083 & .049 & .087 & .065 \\
\hline $\operatorname{corr}(x, Y)$ & -.91 & .49 & .92 & .59 & .90 & -.91 \\
\hline $\operatorname{corr}\left(x, x_{-1}\right)$ & .68 & .17 & .73 & .32 & .73 & .68 \\
\hline
\end{tabular}

The two sets of model results are almost identical, except that the $E N$ and $N E$ transition rates are slightly more cyclical and persistent. Note that in this exercise we have assumed that classification errors do not have a cyclical component. This is consistent with recent work of Elsby, Hobijn, and Şahin (2011).

\section{A.4 Computation}

The computation follows the algorithm which is briefly summarized below and described in more detail later subsequently.

1. Replace $\Omega$ by more limited information that can easily be kept track of. Here, we choose the current aggregate capital stock $K$ and the aggregate capital-labor ratio in the previous period, $M_{-1} \equiv K_{-1} / L_{-1}$, as the information that the consumers use when they make decisions.

2. The consumers have to forecast tomorrow's aggregate capital $K^{\prime}$ and also need to calculate today's aggregate capital-labor ratio $M=K / L$ (to know the prices today). 
We use the following simple forecasting rules:

$$
\log \left(K^{\prime}\right)=a_{0}+a_{1} \log (K)+a_{2} \log (z)+a_{3} \log \left(M_{-1}\right)
$$

and

$$
\log (M)=b_{0}+b_{1} \log (K)+b_{2} \log (z)+b_{3} \log \left(M_{-1}\right)
$$

At the first iteration, make a guess for the values of $a_{0}, a_{1}, a_{2}, b_{0}, b_{1}$, and $b_{2}$.

3. Obtain the prices $r$ and $w$ from $z$ and the forecasted $M$. Obtain $T$ from $w, K$, and the forecasted $M$. Solve the optimization problem of the consumers.

4. Simulate the economy using the decision rules of the consumers obtained above. In particular, we can obtain the time series of $K$ and $M$. Check whether the law of motion for $K^{\prime}$ and the forecasting rule for $M$ guessed above are consistent with the simulated values. That is, run a regression using the simulated data to see if the coefficients conjectured above are identical to the ones obtained from the regression (also check the fit of the regression). If they are different, modify the coefficients and go back to the previous step. Repeat until the coefficients have converged.

We find that this procedure works well in our model, and the resulting forecasting rules are remarkably accurate. This means that even if we add more information to each consumer's information set, the consumer cannot forecast much better.

In detail, the steps are as follows.

1. The aggregate information set $\Omega$ is restricted to a limited set of information. In particular, we limit the information to the current aggregate state $Z$, the current aggregate capital stock $K$, and the aggregate capital-labor ratio in the previous period 
$M_{-1} \equiv K_{-1} / L_{-1}$. Then, the value functions can be rewritten as $V\left(k, z, Z, K, M_{-1}\right)$, $W\left(k, z, Z, K, M_{-1}\right)$, and $N\left(k, z, Z, K, M_{-1}\right)$, where

$$
V\left(k, z, Z, K, M_{-1}\right)=\max \left\{W\left(k, z, Z, K, M_{-1}\right), N\left(k, z, Z, K, M_{-1}\right)\right\}
$$

and the Bellman equations for $W$ and $N$ are given by:

$$
\begin{aligned}
& W\left(k, z, Z, K, M_{-1}\right)= \\
& \quad \max _{c, k^{\prime}}\{\log (c)-\alpha \\
& \left.\quad+\beta E_{z^{\prime}, Z^{\prime \prime}, M}\left[(1-\sigma(1-\lambda)) V\left(k^{\prime}, z^{\prime}, Z^{\prime}, K^{\prime \prime}, z^{\prime}, Z^{\prime}, K^{\prime}, M\right)\right]\right\}
\end{aligned}
$$

s.t. $c+k^{\prime}=r\left(Z, K, M_{-1}\right) k+(1-\tau) w\left(Z, K, M_{-1}\right) z+(1-\delta) k+T\left(Z, K, M_{-1}\right)$

$$
c \geq 0, k^{\prime} \geq 0
$$

and

$$
\begin{aligned}
& N\left(k, z, Z, K, M_{-1}\right)= \\
& \max _{c, k^{\prime}}\left\{\log (c)+\beta E_{z^{\prime}, Z^{\prime}, K^{\prime}, M}\left[\lambda V\left(k^{\prime}, z^{\prime}, Z^{\prime}, K^{\prime \prime}, z^{\prime}, Z^{\prime}, K^{\prime}, M\right)\right]\right\} \\
& \text { s.t. } c+k^{\prime}=r\left(Z, K, M_{-1}\right) k+(1-\delta) k+T\left(Z, K, M_{-1}\right) \\
& c \geq 0, k^{\prime} \geq 0 .
\end{aligned}
$$

2. In order to calculate the right hand sides of the Bellman equations (2) and (3), the consumer has to be able to see the prices today and form an expectations on the future aggregate state variables. We adopt a log-linear forecasting rules:

$$
\log \left(K^{\prime}\right)=a_{0}+a_{1} \log (K)+a_{2} \log (Z)+a_{3} \log \left(M_{-1}\right)
$$


and

$$
\log (M)=b_{0}+b_{1} \log (K)+b_{2} \log (Z)+b_{3} \log \left(M_{-1}\right)
$$

At the first iteration, we make a guess for the values of $a_{0}, a_{1}, a_{2}, b_{0}, b_{1}$, and $b_{2}$.

3. We discretize the state space. For the aggregate shocks, the vector $(Z, \lambda, \sigma)$ can take two possible sets of values - these values vary with experiments, and are detailed in the main text. $z$ is discretized into 20 points. The grids are equally spaced in terms of $\log (z)$, from the minimum of two standard deviations below the mean and the maximum of two standard deviations above the mean. The individual asset has 48 grids for the purpose of the individual optimization, ranging from 0 to 1440 (the average capital holding is 183.7). The grids are (smoothly but) unequally spaced so that there are more grids on the smaller side of $k$ (this is because there is more curvature in the value functions around the smaller values of $k$ ). We set 5 equally spaced grids on $K$ (ranging from 160 to 200 for the benchmark) and 5 equally spaced grids on $M_{-1}$ (ranging from 145 to 185 for the benchmark).

For each aggregate state (and using (5), the prices and the transfer can be calculated as

$$
\begin{gathered}
r=\theta Z M^{\theta-1}, \\
w=(1-\theta) Z M^{\theta},
\end{gathered}
$$

and

$$
T=\tau w \frac{K}{M}
$$

Then we perform the optimization at each grid point and iterate over the value functions in order to solve the Bellman equations (2) and (3). Along $K^{\prime}$ and $M$ directions, the value functions are interpolated using a polynomial interpolation where necessary. A 
linear interpolation is used in $k^{\prime}$ direction. We start from the guesses on $V$ and $N$ functions, then obtain the new $W$ function and the new $N$ function from the right hand sides of (2) and (3), and then obtain the new $V$ function from (1). We search for optimal asset decision globally using golden section search. We use global method without differentiation (with linear interpolation) because of potential nonconcavity and nondifferentiability due to the discrete labor-leisure choice.

4. Once the Bellman equations are solved (and we have the value functions and the policy functions for the asset choice), we simulate the economy. In particular, we draw 5000 periods of the aggregate shocks, start from the stationary distribution of (asset, productivity, employment) in the steady state model, and iterate over the density functions. For this simulation, we increase the number of grids in $k$ direction to 12001 . (The policy functions are linearly interpolated in $k$ direction. For $K$ and $M_{-1}$ directions, polynomial interpolations are used where necessary.)

The detail of the simulation is as follows. We have a mass of consumers on a particular grid of (asset, productivity, employment). Given the current aggregate state, we know how this mass is divided and moved into the next period (asset, productivity, employment) grids, given the policy functions and the transition probabilities.

Two details to note here - for the asset direction, since the decision rules are continuous, most likely $k^{\prime}$ won't fall on the exact grid point. We divide the mass linearly in that case - if the decision rule says that $k^{\prime}$ for a particular (asset, productivity, employment) combination would be $0.3 k_{n}+0.7 k_{n+1}$ (where $n$ is the index of the grid point), then we allocate $30 \%$ of people on $k_{n}$ and $70 \%$ of people on $k_{n+1}$ in the next period. For the employment direction, we have to decide whether the people who moved to a particular (asset, productivity, employment) would work or not in the next period in the cases 
where they have a choice. This can simply be done by comparing $W$ and $N$ next period at each grid points, given the next period aggregate state. One drawback of this simple method is that the employment distribution will be the same between the case where $\left(W_{n}>N_{n}, W_{n+1} \ll N_{n+1}\right)$ and $\left(W_{n} \gg N_{n}, W_{n+1}<N_{n+1}\right)$ (where the subscript is the grid index of $k^{\prime}$ where the value function is evaluated), and the labor supply can potentially jump with a small change in environment if the threshold value crosses a grid point. In order to "smooth out" this effect, we linearly interpolate the employment decision based on the distances of the value functions at each grid points. In effect, we are supposing that consumers are distributed uniformly between $k_{n+1}$ and $k_{n}$ instead of having a mass at $k_{n}$ (except at the maximum grid point) and approximating the value function by linear interpolation in between these grids. ${ }^{22}$

Once the simulation is done, we have a time series of $\left(Z, K, M_{-1}\right)$. Using this time series (discarding the first 1000 periods), we run OLS regressions (4) and (5). We repeat the same steps until the coefficients converge.

The converged forecasting equations are

$\log \left(K^{\prime}\right)=0.050234+1.004265 \log (K)+0.000514 \log (Z)-0.014181 \log \left(M_{-1}\right), R^{2}=0.999998$

and

$\log (M)=-0.147328+0.280710 \log (K)-0.070561 \log (Z)+0.742800 \log \left(M_{-1}\right), R^{2}=0.990492$

for the experiment with only frictions $\left(Z_{G}=1.016\right.$ and $Z_{B}=0.984$ are used for the purpose

\footnotetext{
${ }^{22}$ This smoothing method introduces a small downward bias in the level of labor supply, but this effect is negligible given the large number of grids. We cross-checked with the simulation with a large number of individuals and the behavior of aggregate variables is almost identical. Clearly one can use a more elaborated method of adjustment, but we choose this method due to its simplicity.
} 
of these forecasting rules),

$\log \left(K^{\prime}\right)=0.064087+0.991358 \log (K)+0.027667 \log (Z)-0.003739 \log \left(M_{-1}\right), R^{2}=1.000000$

and

$\log (M)=-0.658345+0.828787 \log (K)-0.276471 \log (Z)+0.284357 \log \left(M_{-1}\right), R^{2}=0.998948$

for the case of $Z$ only, and

$\log \left(K^{\prime}\right)=0.061413+0.993660 \log (K)+0.028053 \log (Z)-0.005560 \log \left(M_{-1}\right), R^{2}=1.000000$

and

$\log (M)=-0.558708+0.745101 \log (K)-0.326600 \log (Z)+0.350141 \log \left(M_{-1}\right), R^{2}=0.999771$

for the benchmark case.

Once all above is done, we simulate many consumers to obtain the statistics of interest. (In this simulation, we do not need any interpolation for the next period employment - we simply compare the value function.) We simulate 100,000 people to obtain the statistics of the tables. For the "impulse response" diagrams, we simulate 10,000,000 people. 